\title{
Die Orte des literarischen Reiseberichts: Abschied - Höhepunkt - Ankunft - Abreise vom Ziel - Rückkunft
}

Topographien und Topologien spielen im literarischen Reisebericht eine zentrale Rolle. Der Reisebericht ist als literarisches Genre tief in ein System von Verortungen eingesenkt und führt die Orte mit ihren jeweiligen Koordinaten in seinen Beschreibungen vor. Auf diese Weise ist der Reisebericht eine Gattung des Ortes, genauer: des Ortswechsels, der Ortsveränderung und der ständig neuen Ortsbestimmung. Den Reisebewegungen lassen sich dabei eine Reihe typischer Orte zuweisen. Dies klingt selbstverständlich, ja banal; und doch wurde dieser Aspekt in seinen spezifisch ästhetischen Auswirkungen noch nicht ausreichend durchdacht und literaturtheoretisch reflektiert. Dies aber ist das Ziel der nachfolgenden Überlegungen. Dabei soll es freilich weniger um die Orte an sich, als um eine Poetik der Bewegung gehen, die sich an die jeweiligen Orte anknüpft und diese in eine Bewegung, in eine grundlegende Mobilität einbindet.

Dabei ist deutlich: Die Topoi und Orte des Reiseberichts sind bislang vorwiegend unter ihrem referentialisierbaren, textexternen, also auf die außersprachliche Wirklichkeit bezogenen Aspekt untersucht worden. Wir suchen danach, die weiblichen und männlichen Reisenden in Raum und Zeit zu verorten und genau zu klären, ob ein Reisender oder eine Reisende an einem bestimmten Ort sich aufhielt oder nicht. In allen Reiseberichten erscheinen die Koordinaten eines Itinerariums, das uns ständig vor Augen geführt, aber auch beständig überprüft wird. Der Reisende bewegt sich zwischen diesen Orten und fädelt sie, zumindest in der 'klassischen' Version, nacheinander zu einer Abfolge von Ortsveränderungen auf. Der literarische Reisebericht wird so, im Sinne von Ralph-Rainer Wuthenow, zu einer erfahrenen Welt: Die Erfahrung wird als Bewegungsmetaphorik konkret greifbar und 'erfahrbar'.

In diesem Sinne entsteht ein Netz von Orten, das den Reisebericht durchzieht und ihm, gerade im 18. und 19. Jahrhundert, seine Stabilität und Sicherheit verleiht. Wir setzen als Leser ganz selbstverständlich voraus, dass uns der Bericht von einer Reise von Ort zu Ort führt und wir diese Bewegung auf einer Landkarte mit dem Finger nachvollziehen können. Und in der Tat ist vielen Reiseberichten ein allgemeines und spezielles Kartenmaterial beigegeben, das alle Bewegungen der Reisenden im Raume nachvollziehbar macht.

Diese textextern referentialisierbare Ebene betrifft vorwiegend den im Genette'schen Sinne diktionalen Charakter von Reiseliteratur: Er verortet sich in

Ә Open Access. (C) 2020 Ottmar Ette, publiziert von De Gruyter. (cc) BY-NC-ND Dieses Werk ist lizenziert unter der Creative Commons Attribution-NonCommericial-NoDerivatives 4.0 Lizenz. 
der Materialität des Reisens und ist jederzeit anhand konkreter Überprüfungen unmittelbar nachvollziehbar. So ließe sich im Sinne der Terminologie Numa Brocs zu Recht fragen, ob ein im Reisebericht erwähnter Ort vom Schriftsteller nicht nur dargestellt, sondern tatsächlich auch besucht, gesehen wurde - mit anderen Worten: ob die oder der Reisende als Augenzeugen und Gewährsleute des Berichteten auftreten können oder nicht. Vom Ergebnis dieser Nachforschungen hängt eine Fülle von konkreten Einschätzungen und Klassifizierungen des jeweiligen Reiseberichts ab. Jeder Reisebericht muss sich dieser Frage stellen und ordnet sich unterschiedlichen Subgattungen zu, je nachdem, wie die Antwort auf diese Frage nach dem Verhältnis zur außersprachlichen Wirklichkeit ausfällt. Wir bewegen uns hier wohlgemerkt noch immer ganz im Feld der Diktion, gleichsam auf sicherem Terrain.

Dies aber kann nur ein Lektüremodus des Reiseberichts sein, also eine Art und Weise, wie ein bestimmter Reisebericht gelesen werden darf oder soll. Zwischen einer auf diese Weise institutionalisierten Lektüre einerseits und der Lektüre phantastischer Reiseberichte andererseits aber lässt sich ein Lektüremodus denken, der zwischen dem 'Realitätskonformen' und dem 'Fiktionalen' ständig pendelt, um die Polysemie des untersuchten Textes nicht durch textexterne Referentialisierung oder innerliterarische Fiktionalisierung zu vermindern und $\mathrm{zu}$ fixieren, kurz: die Bewegungsvielfalt, Dynamik und Unbestimmtheit des Reiseberichts einzugrenzen und $z u$ beschränken. Denn wir hatten bereits gesehen, dass eine Reduktion des Reiseberichts auf sein Verhältnis zur außersprachlichen Realität nicht nur nicht überzeugend ist, sondern der Gattung des Reiseberichts gegenüber als unbefriedigend, ja als impertinent erscheint. Der literarische Reisebericht ist weit mehr als die krude Ausleuchtung einer textexternen Materialität, die es zu bestätigen oder zu verwerfen gilt. Es kommt darauf an, unsere Lektüremodi an die breit gefächerte Polysemie des literarischen Reiseberichts anzupassen und die Vieldeutigkeit dieses Genres zu erhalten.

Dazu aber bedarf es spezieller Lektüremuster, mit deren Hilfe wir uns den Reiseberichten nähern und sie deuten können. Orte sind freilich mehr als Koordinaten im Raum, die wir ermitteln beziehungsweise korrigieren. Es geht folglich um die Gewinnung reiseliterarischer Orte, die auf einer höheren Abstraktionsebene als die Toponymien selbst angesiedelt sind. Wie aber können wir diese Orte ermitteln?

Ein reiseliterarischer Ort ist eine bestimmte Position, der eine Vektorizität innerhalb eines Verlaufes eingeschrieben ist und die aus dieser Vektorizität ihre eigene semantische 'Füllung' bezieht. Es geht folglich nicht um rein räumliche Koordinaten, sondern um Bewegungs-Orte, die eine hohe semantische Dichte aufweisen und daher als Interpretament für sich anschließende Deutungen dienen können. Die gesuchten Orte sind Markierungen in einem narrativen 
und bisweilen itinerarischen Verlauf, ohne doch wiederum auf diese konkreten Verläufe reduziert zu werden. Sie geben eine Ökonomie des Reiseberichtes, vielleicht auch einen Spannungsbogen vor oder legen eine derartige Ökonomie der eigentlichen narratio doch nahe. Sie bilden entscheidende Momente einer reiseliterarischen Erzählung und in jedem Falle Orte einer unverkennbaren semantischen Verdichtung und Konzentration. Kurz und gut: Sie machen Sinn auf mehr als einer Bedeutungsebene, auf mehr als einer Isotopie. In der Folge sollen exemplarisch vier verschiedene reiseliterarische Orte herausgearbeitet werden, die für den literarischen Reisebericht von besonderer Relevanz sind und ihn mit einer spezifischen Vektorizität versehen. es sind Orte von hoher semantischer Verdichtung.

\section{Erstens: Der Abschied}

Reiseliterarische Orte punktieren und semantisieren den literarischen Reisebericht und stellen Orte von erhöhter Signifikanz und Vektorizität dar. Fragen wir mithin nach jenen Orten, an denen die Reiseschriftstellerinnen und -schriftsteller ihre Berichte in besonderer Weise semantisch aufladen und markieren, fragen wir also nach spezifischen Formen der dispositio, so können wir aus der großen Zahl von Möglichkeiten einige Grundmuster und topische Einschnitte reiseliterarischer Orte herausfiltern, deren erster der Ort des Abschiednehmens ist.

An diesem reiseliterarischen Ort geht es folglich um den Abschied vom Eigenen, von der eigenen Herkunft und - wenn Sie so wollen - von der jeweiligen Heimat der Autorin oder des Autors. Dabei sind verschiedenste Varianten der Inszenierung und Verabschiedung vom Hort des Eigenen vorstellbar - bis hin zu der Variante, dass dieser Ort eigener Herkunft im jeweiligen Akt des Abschieds erst bestimmt und hervorgebracht wird.

Dieser reiseliterarische Ort kann - wie etwa in der Voyage à l'île de France des jungen Bernardin de Saint-Pierre - in der Form des Abschieds von geliebten Menschen oder von liebgewonnenen Formen der Natur inszeniert werden, so dass die Dimension intensiven menschlichen Erlebens (und damit die Position des erzählten Ich) in den Vordergrund gerückt wird und einer affektiven Schau die Bühne eröffnet. Die inneren Bewegungen des Ich gehen gleichsam den Bewegungen der eigentlichen Reise voraus oder werden parallel mit diesen ersten Reisebewegungen für die Leserschaft erfahrbar gemacht. So lesen wir in Bernardin de Saint-Pierres Voyage à l'Ile de France in einer besonders sorgfältig verfassten Passage: 
Ich höre den Lärm der Pfeifen und wie sich die Winde empordreht und die Matrosen, die den Anker lichten ... Der letzte Kanonenschuss wird abgefeuert. Die Segel sind gesetzt; ich sehe das Ufer, die Befestigungen und die Dächer von Port-Louis schwinden. Adieu, ihr Freunde, die ihr mir teurer als alle Schätze der Kolonien seid! ... Adieu, ihr Wälder des Nordens, die ich nie wiedersehen werde! Zarte Freundschaft! Und noch zärtlicheres Gefühl, das sie übertrifft! Zeit des Rausches und des Glückes, die wie ein Traum verflogen ist! Adieu ... adieu ... Man lebt nur einen Tag, um dann das ganze Leben lang zu sterben.

[...]

Am 5. kam ein schweres Unwetter auf. Das Schiff segelte unter den beiden Focksegeln. Ich war sehr erschöpft von der Seekrankheit. Um halb elf Uhr vormittags, als ich auf meinem Bett lag, spürte ich plötzlich einen starken Stoß. Jemand schrie, das Schiff sei auf Grund gelaufen. Ich stieg auf die Brücke, wo alle bestürzt beisammen standen. Eine Woge von Steuerbord hatte die Jolle oder kleine Schaluppe, den Bootsmann und drei Männer mit sich aufs Meer hinausgerissen. Ein einziger von ihnen klammerte sich noch an die Taue des großen Mastes, seine Schulter und seine Hand waren zerschmettert, aber er konnte in Sicherheit gebracht werden. Es war unmöglich, auch die anderen $\mathrm{zu}$ retten: wir haben sie nicht wiedergeseh. ${ }^{1}$

Teilübersetzung: „Der letzte Kanonenschuss wird abgefeuert. Die Segel sind gesetzt; ich sehe, wie das Ufer, die Befestigungen und die Dächer von Port-Louis schwinden. Adieu, ihr Freunde, die ihr mir teurer als alle Schätze der Kolonien seid! ... Adieu, ihr Wälder des Nordens, die ich nie wiedersehen werde!“

Bernardin de Saint-Pierre hat in seinem von den Zeitgenossen nur mäßig goutierten Reisebericht die Abschiedsszene mit größter Aufmerksamkeit gestaltet. Das Unglück gleich zu Beginn der Reise wirft einen Schatten auf die gesamte Reise und kann als ein übles Vorzeichen gedeutet werden. Alles erscheint in einem Licht, das nichts Gutes erahnen lässt. Wird der Reisende jemals wieder in sein Vaterland zurückkehren können? Alle Fragen, alle Befürchtungen bleiben vorerst ohne Antwort. Die Reise hat jedoch noch kaum begonnen, da sind bereits zwei Tote zu beklagen. Ein entspannter Aufbruch sieht anders aus.

Genau genommen findet sich in Bernardin de Saint-Pierres Band eine Verdoppelung des reiseliterarischen Ortes des Abschieds, insoweit der Abschied von Europa nicht nur in der präsentischen Form des Briefes, sondern ein zweites Mal in jener des unmittelbar im Anschluss eingerückten Journal, des Schiffstagebuches also, dargestellt wird. Hier sind es die nautisch relevanten Angaben, aber auch ein Unfall, bei dem drei Mann der Besatzung kurz nach dem Ablegen noch an der bretonischen Küste den Tod finden. Das eigene intensive Erleben des erzählten Ich und der Bericht im Tagebuch überschneiden sich und blenden die

1 Saint-Pierre, Bernardin de / Benot, Yves (Hg.): Voyage à l’île de France. Paris: La Découverte 1983, S. $36 \mathrm{f}$. 


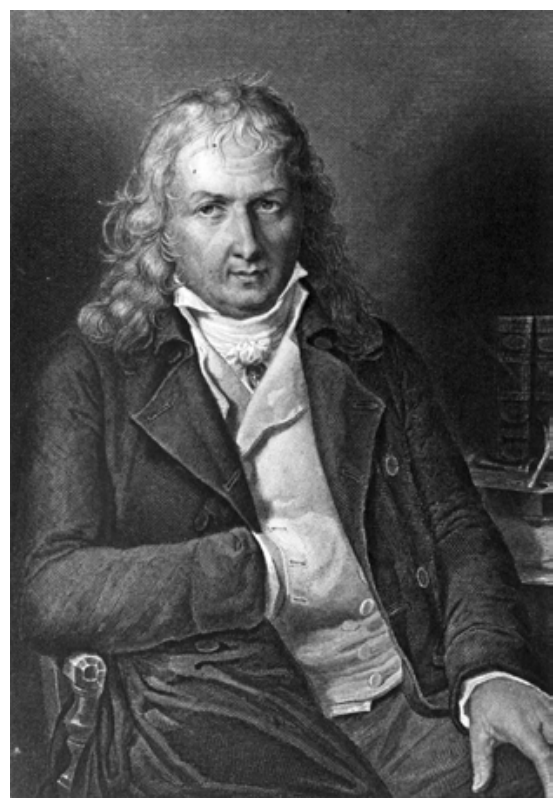

Abb. 29: Bernardin de Saint-Pierre (Le Havre, 1737 - Éragny, 1814).

Fragwürdigkeit des Verlassens Frankreichs ein, die den Reisenden auf seiner Fahrt begleiten wird. Von Beginn an ist das Ich auf sich allein gestellt, die (politische) Führung des Unternehmens versagt ganz so, wie die Leitung der Kolonie in den Augen des Ich ebenfalls versagen wird. die Reise nach Mauritius steht von Beginn an wahrlich unter keinem guten Stern.

Die reiseliterarischen Vorkehrungen und Verfahren sind durchaus komplexer Natur. Bernardin de Saint-Pierres Bericht ist hier insoweit aufschlussreich, als er eine Doppelperspektive entwickelt, die es erlaubt, über die Form des (literarischen) Briefes die Innenwelt des Reisenden und über die vorgeblich nüchternere Form des Schiffstagebuchs das auf die Außenwelt gerichtete Erleben jeweils des erzählten Ich darzustellen. Dieses Ich wird gleichsam multiperspektivisch reflektiert durch eine Innensicht und eine kontrastiv dazu gestellte $\mathrm{Au}$ ßensicht, die beide freilich miteinander interferieren. Für die Leserinnen und Leser erscheint das (erzählte, reisende) Ich damit zumindest aus einer doppelten Perspektive.

Die Hybridität des Reiseberichts erlaubt nicht nur den bloß flüchtig miteinander verbundenen Einsatz zweier sehr unterschiedlicher Gattungen, sondern auch die zweifache Perspektivierung schmerzhafter Trennung und gefährlichen Aufbruchs zu einer langen Reise in die außereuropäische Welt. Das Ich erscheint im Blickwechsel ständig sich verändernder Gesichtspunkte, wobei die 
Zukunftsoffenheit allen Geschehens in der Jetztzeit des Reiseberichts doppelt eingefangen wird.

Diese Doppelung führt gleichsam nebenbei ein eigentümliches Oszillieren zwischen der literarischen Darstellung individuellen Erlebens und referentialisierbaren, vorgegebenermassen an Faktentreue sich orientierenden Schreibformen ein, was den friktionalen Charakter des Textes unterstreicht. Denn wir haben auf der einen Seite die objektivierbaren Fakten, Koordinaten und Messungen; auf der anderen Seite aber haben wir ein Ich vor uns, das sich uns in seinen intimsten Gedanken und Gefühlsregungen in einer vorromantischen Form subjektiver Offenheit zeigt.

Der Abschied vom Eigenen kann aber auch eine weitergehende Reflexion miteinschließen, die das Eigene in neuer Weise perspektiviert. So kann der Abschied vom Eigenen etwa der Abschied von den Liebsten, von einer Familie, einem Dorf oder einer Stadt, aber auch von einer Nation oder einer supranationalen Einheit sein, die einen ganzen Kontinent miteinbegreift. So wohnen wir bei Alexander von Humboldt einer Szenerie bei, welche uns die Geburt eines Europäers zeigt - jenes Europäers, zu dem Humboldt Stück für Stück wurde, ohne sich selbst in Kriegszeiten (sehr zum Missvergnügen der Nationalisten seiner Zeit) auf die eine oder andere Seite zerren zu lassen:

Bei Einbruch der Nacht wurde die See sehr unruhig, und der Wind frischte stark auf. Wir steuerten gegen Nordwest, um nicht den englischen Fregatten zu begegnen, die, wie man glaubte, in diesen Zonen kreuzten. Gegen neun Uhr sahen wir das Licht einer Fischerhütte von Sisarga, das letzte, was uns von der Küste Europas zu Gesicht kam. Mit zunehmender Entfernung verschmolz der schwache Schimmer mit dem Licht der Sterne, die am Horizont aufgingen, und unwillkürlich blieben unsere Blicke daran hängen. Dergleichen Eindrücke vergißt einer nie, der in einem Alter, wo die Empfindung noch ihre volle Tiefe und Kraft besitzt, eine weite Seereise angetreten hat. Welche Erinnerungen werden in der Einbildungskraft wach, wenn so ein leuchtender Punkt in finsterer Nacht, von Zeit zu Zeit aus den bewegten Wellen aufblitzend, die Küste des Heimatlandes bezeichnet! ${ }^{2}$

Die Szene des Abschieds vom Eigenen ist hier mit Bedacht und ebenfalls sehr sorgfältig ausgeführt. Sie geht auf Humboldts Amerikanische Reisetagebücher zurück, wo sie bereits in allen wesentlichen Aspekten festgehalten worden war. In seiner Relation historique, dem eigentlichen Reisebericht seines großangelegten Reisewerkes, gestaltet er diesen reiseliterarischen Ort aber noch subtiler. Denn ist das Eigene nicht schon ein Fremdes, ein Zeichen zwar der Alten Welt, aber doch eines anderen Landes, einer anderen Macht?

2 Humboldt, Alexander von / Ette, Ottmar (Hg.): Reise in die Äquinoktial-Gegenden des Neuen Kontinents. 2 Bde. Frankfurt a. M. : Insel 1991, Bd. 1, S. 65 f. 
Alexander von Humboldt hat an dieser Stelle seines Reiseberichts ein schwaches und bald schon verschwindendes Lichtzeichen der spanischen Küste eingeführt, das den Ort der Trennung vom Eigenen markiert. Dabei wird das Eigene insoweit neu perspektiviert, als die spanische Küste zur Küste des eigenen pays natal wird, das dem Preußen zunächst fremde Spanien sich also zum größeren Europa hin öffnet und sich in das Eigene (oder vielleicht genauer noch: in das Fremde im Eigenen) verwandelt. Das Geburtsland, das pays natal, ist fortan das größere Europa: Alexander von Humboldt stellt reiseliterarisch dar, wie er zum Europäer wurde: just in jenem Augenblick, als er Europa verließ.

Zugleich führt dies eine erste, noch implizite Reflexion über die eigene Wahrnehmung ein, wird doch nun der Reisende als Europäer, als Bewohner der Alten Welt, die sogenannte Neue Welt er-fahren und portraitieren. Damit ist der gewählte Blickwinkel, unter dem die Dinge erscheinen werden, klar bezeichnet und kenntlich gemacht. So wird im Reisebericht nicht nur die Ebene individuellen Erlebens aus der Perspektive des erzählten Ichs markiert, sondern gleichzeitig aus der Distanz des erzählenden Ichs, das auf sein Gedächtnis und das dort für immer Aufbewahrte zurückgreifen kann. Auch hier also ergibt sich wie bei Bernardin de Saint-Pierre eine Doppelperspektivität, die freilich aus der Differenz zwischen erzähltem und erzählendem Ich heraus entsteht.

Folglich wird ein Oszillieren zwischen Erleben und distanziertem Erzählen eingeführt, welches Humboldt in der Folge immer wieder eine Spiegelung der Wahrnehmungsbedingungen sowie eine Kommentierung auf abstrakterer, 'philosophischer' Ebene erlaubt. Die Einführung von Funktion und Figur eines wissenschaftlichen Ich garantiert überdies die Zuverlässigkeit und Präzision der erhobenen Daten, die überall in den Reisebericht eingestreut werden und das außersprachlich Referentialisierbare bezeichnen. Die tatsächliche Existenz der Fischerhütten von Sisarga rückt freilich angesichts einer derart vieldeutigen semantischen Aufladung weitgehend in den Hintergrund, ohne allerdings gänzlich $\mathrm{zu}$ verschwinden, geben sie dem Leser doch die eingeschlagene Route des Schiffes bekannt. Hier kann gelten: Se non è vero e ben trovato! Humboldt vermochte es geschickt, die europäische Perspektivierung seines Blickes auf die Neue Welt gleich am reiseliterarischen Ort des Abschieds wirkungsvoll anzukündigen.

Eine Variante bei der Gestaltung dieses reiseliterarischen Ortes des Abschieds und seiner philosophischen Implikationen findet sich in Guillaume-Thomas Raynals umfangreichem 'Bestseller' der zweiten Hälfte des 18. Jahrhunderts über die koloniale Expansion Europas. Nur wird das Europäertum der europäischen Reisenden in einen negativen, kolonialistischen Kontext eingerückt und zugleich eine Warnung ausgesprochen. Dort erscheint das Passieren der Äquatorlinie - das von Mannschaften und Passagieren im Übrigen stets in einer 
teilweise ritualisierten Form gefeiert wurde - als entscheidender Punkt einer keineswegs schmeichelhaften Veränderung von Bewusstsein und Verhalten aller Reisenden:

Ist der Äquator erst überschritten, so ist der Mensch weder Engländer oder Holländer noch Franzose, Spanier oder Portugiese. Er behält von seinem Vaterland nur die Prinzipien und Vorurteile bei, die sein Verhalten begründen oder entschuldigen. Kriecherisch, wenn er schwach, gewalttätig, wenn er stark ist; dem Drange ausgeliefert, zu erwerben und zu genießen; und er ist aller Missetaten fähig, wenn diese ihn schneller zu seinen Zielen führen. Er ist ein domestizierter Tiger, der in den Urwald zurückkehrt. Der Durst nach Blut ergreift wieder von ihm Besitz. Auf diese Weise haben sich unterschiedslos alle Europäer in den Gebieten der Neuen Welt gezeigt, wohin sie einen gemeinsamen Wahn mitnahmen, den Durst nach Gold. ${ }^{3}$

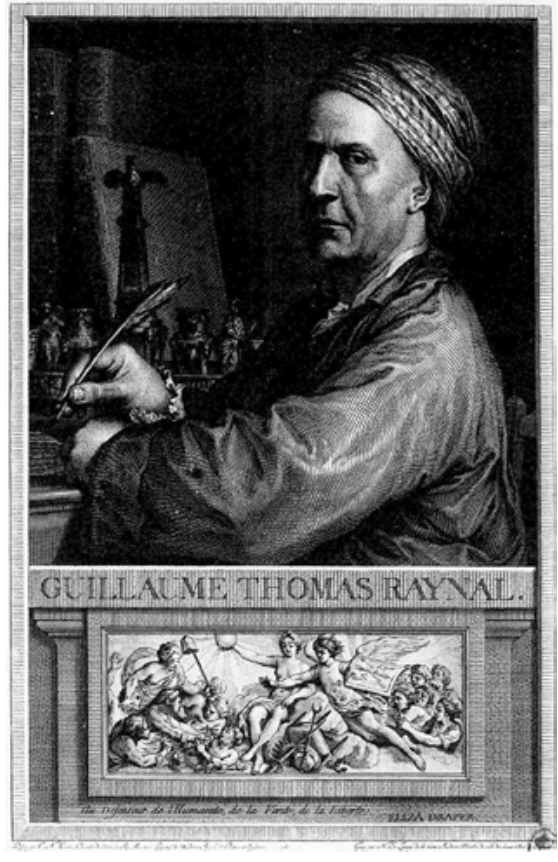

Abb. 30: Guillaume-Thomas Raynal (Lapanouse, 1713 - Chaillot, 1796).

3 Raynal, Guillaume-Thomas: Histoire philosophique et politique des établissemens et du commerce des européens dans les deux Indes. Tome cinquième. Genève: Chez Jean-Léonard Pellet 1781, livre neuvième, S. 2. 
Hier erfolgt die Verwandlung von Spaniern und Engländern, Holländern und Portugiesen in Europäer unter dem gemeinsamen Signum von Raubtieren, die im Urwald außerhalb Europas auf brutalem Beutezug sind. Man hätte diese Metamorphose von Menschen in gefräßige, blutdürstende Tiger kaum treffender auf den Punkt bringen können als in dieser eindrücklichen Passage, die aus der Feder von Denis Diderot stammt. Europa steht hier nicht für Ausgleich, Dialog und Offenheit, sondern für Habgier, Raub, Mord und alle Gräuel des Kolonialismus.

Doch bleiben wir noch einen Augenblick bei transatlantischen Reisen und Reisenden des 18. Jahrhunderts. Bei Reisen nach Amerika beziehungsweise nach Übersee fällt der Abschied von Europa zusammen mit dem Übergang von einer Land- oder Binnenreise zu einer Seereise. Ein solcher epistemologisch höchst bedeutsamer Wechsel wird im Reisebericht in aller Regel hervorgehoben und nicht selten auch wahrnehmungstheoretisch reflektiert. Dafür sei noch ein letztes Beispiel benannt.

Georg Forster hat in seinen Ansichten vom Niederrhein - die in mancherlei Beziehung zu den Ansichten der Natur Humboldts stehen, der im Übrigen den früheren Weltumsegler bei dieser Reise begleitete - den Anblick des Meeres zum Anlass genommen, nicht nur auf seine gut zwölf Jahre zurückliegende Weltumrundung mit James Cook zurückzublicken, sondern daran auch philosophische Reflexionen zu knüpfen, ${ }^{4}$ von denen der Reisebericht des ausgehenden 18. Jahrhunderts in Deutschland wie in Frankreich so gesättigt ist. Land und Meer markieren hier eine Grenze, der auf der Ebene des Reiseberichts, selbst bei Reisen innerhalb Europas, man denke nur an Johann Wolfgang Goethes Überfahrten zwischen Sizilien und der neapolitanischen Küste in seiner Italienischen Reise, ein eigener reiseliterarischer Ort zukommt. Man könnte im Übrigen hier, beim Übergang von der Landreise zur Seereise, einen eigenen reiseliterarischen Ort konstatieren, der freilich stets die Dimensionen eines Abschieds vom Eigenen fortspinnt.

Damit einher geht ein signifikanter Wechsel des Fortbewegungsmittels, folglich eine infrastrukturelle Diskontinuität mit Folgen. Ein solcher Wechsel deutet oft einen Wechsel der Wahrnehmungsperspektive an, der - wie beim Übergang von der Landreise zur Flussfahrt in La Condamines Voyage sur l'Amazone - stets vom erzählenden Ich dazu benutzt wird, die spezifisch referentielle narrative Ebene des Berichtens $\mathrm{zu}$ verlassen. ${ }^{5}$ Das jeweils gewählte

4 Vgl. Wuthenow, Ralph-Rainer: Die erfahrene Welt, S. 388.

5 Die eigene Position ist bei der Flussfahrt als eine sich in Bewegung befindliche, nirgends länger verweilende Perspektive eines „voyageur qui ne voit les choses qu'en passant“, also eines Reisenden, der die Dinge nur aus der Vorbeifahrt sieht, markiert; vgl. Condamine, 
Fortbewegungsmittel vermittelt eine mediale Perspektivik, die im Reisebericht oft zu Bewusstsein gebracht und zum Teil auch kritisch reflektiert wird.

Ein Wechsel der den Reisenden umgebenden Landschaft beinhaltet häufig ein Bewusstmachen eigener theoretischer Positionen: Die Theorie der Landschaft schlägt um in eine Landschaft der Theorie, mit deren Hilfe eine ganze Epistemologie der eigenen Reiseunternehmung einhergeht. Die Landschaft dient als Visualisierung theoretischer Konzepte, die dem oder der Reisenden lieb und teuer sind. Landschaft wird zum Ausgangspunkt und mehr noch zur Inszenierung von Theorie und theoretischer Konzepte. Die referentialisierbaren Bewegungen des Reisenden entsprechen auch bei La Condamine in komplexer Weise Bewegungen des Verstehens und Vermittelns, die aus dem Zusammenspiel von erzähltem und erzählendem Ich an den Leser weitergegeben werden. Die erfolgreiche Inszenierung dieses Zusammenspiels trug zum Erfolg seines Reiseberichts ganz wesentlich bei.

Doch vergessen wir darüber die Leserin oder den Leser nicht. Denn sie sind es, die schließlich über Erfolg oder Misserfolg eines Reiseberichts entscheiden. Dem Aufbruch zur Reise auf der Textebene entspricht die Bewegung des Lesers, der sich darauf einlässt, das Eigene zu verlassen und sich der Reise im fremden Text anzuvertrauen. Er folgt einer invitation au voyage und weiß noch nicht, wohin ihn diese Reise führen wird. Gerade auch aus diesem Grunde ist die Markierung dieses reiseliterarischen Ortes des Abschieds häufig sehr prägnant, wobei ihr nicht selten - wie auch in Bernardin de Saint-Pierres Reisebericht - eine ausführliche Darstellung des Eigenen, in diesem Falle der Bretagne, vorgeschaltet wird. Das Lesepublikum soll wissen, was es am Eigenen hat. Der Abschied von diesem Eigenen wird meist kontrastiv modelliert. Der Kontrast, der sich zwischen zwei Landschaften und Kulturen ergibt, treibt deren jeweilige Theorie und Epistemologie hervor: Deren Visualisierung und Veranschaulichung entsteht in einer Landschaft der Theorie, der die Vektorizität eingeschrieben ist.

\section{Zweitens: Der Höhepunkt}

Ein im Reisebericht zweifellos nicht weniger wichtiger Ort betrifft jenen Abschnitt der Reise, der vom Reiseschriftsteller oder der Reiseschriftstellerin als Höhepunkt und eigentliches Herzstück des Reiseberichts stilisiert wird. Dabei ist dieser Höhepunkt stets auch an einem ganz bestimmten Lesepublikum

Charles-Marie de la: Voyage sur l'Amazone. Introduction et notes de Hélène Minguet. Paris: Maspero 1981, S. 62. 
ausgerichtet, das erreicht werden soll. Denn Höhepunkte lassen sich gewiss viele finden und kennzeichnen; einen bestimmten Punkt als eigentlichen Höhepunkt auszumachen und zu markieren, bedeutet aber eine ganz besondere Leistung und semantische Verdichtung des literarischen Reiseberichts.

Benennen wir also auch hier einen solchen Punkt in einem konkreten Reisebericht als ästhetisch gestalteten reiseliterarischen Ort. Eine recht spektakuläre Inszenierung eines Höhepunktes findet sich in der bereits erwähnten Amazonasfahrt des Mitglieds der französischen Académie des Sciences, Charles-Marie de la Condamine, der 1745 in seinem Vortrag vor dieser Institution seine Reise nach Peru und den mehrjährigen Aufenthalt in der Andenregion fast vollständig ausblendete, dza ein anderes Mitglied dieser Expedition, Pierre Bouguer, mit dem er noch jahrelang im Streit liegen sollte, bereits ein Jahr zuvor der Académie einen Bericht vorgelegt hatte. Es galt für den durch seinen Reisebericht berühmt gewordenen Franzosen folglich, den Höhepunkt aus dem Andenraum weg zu verlagern und eine andere Region zu priorisieren, wollte er vermeiden, lediglich der zweite Berichterstatter von der mit Spannung erwarteten Reise der französischen Akademiker gewesen zu sein. Bouguer war nur zu übertreffen, wenn man ihn ästhetisch überbot, die friktionalen Aspekte in den Vordergrund stellte und zugleich den eigentlichen Höhepunkt der Reise von den Äquatorialvermessungen wegverlegte in einen Bereich, der mit dem eigentlichen Ziel der Reise gar nichts $\mathrm{zu}$ tun hatte. Genau dies tat der französische Académicien - mit großem Erfolg.

La Condamine besaß mithin gute Gründe, gerade jenen Teil seines Aufenthalts in den amerikanischen Kolonien Spaniens hervorzuheben, bei dessen Darstellung er keine unliebsame Konkurrenz durch einen früher zurückgekehrten Reisenden fürchten musste. So erscheint die Reise durch die Anden, die einen langen Forschungsaufenthalt in dieser Region abschloss, wie eine Einleitung, wie ein Vorspiel zu jenem Abschnitt seiner Rückreise nach Frankreich, die ihn stromabwärts auf dem Amazonas bis zu dessen Mündung ins Meer den zentralen Teil Südamerikas in west-östlicher Richtung durchqueren ließ. Die Fahrt auf dem Amazonas wird zum Filetstück des Reiseberichts von La Condamine.

Es galt also vordringlich, einen Ablauf zu konstruieren, welcher den Abstieg in die Niederungen des Amazonas-Tieflandes nicht nur nicht als einen Spannungsabfall, sondern als den eigentlichen Spannungsaufbau schildern musste. Der Eintritt in diese neue, herausgehobene Phase seiner Reise erfolgt durch den Pongo de Manseriche, einen letzten Riegel der Anden, den der obere Marañón durchqueren muss, bevor er ins tropische Tiefland hinaustritt. Der Pongo eignete sich folglich vortrefflich, um eine semantische Veränderung und Verdichtung der gesamten Reise zu bewerkstelligen. Dabei vergisst La Condamine nicht, die ihm lauschenden Akademiemitglieder darauf aufmerksam zu 
machen, dass der Begriff 'Pongo' wohl am besten mit Tor zu übersetzen sei. So tritt sein eigener Reisebericht selbst durch dieses Tor in eine neue Phase ein und leitet über zum eigentlichen Höhepunkt der gesamten Reise:

In Borja angekommen, fand ich mich in einer neuen Welt wieder, weitab von jedem menschlichen Verkehr, auf einem Meer von Süßwasser, inmitten eines Labyrinths aus Seen, Flüssen und Kanälen, die in allen Himmelsrichtungen einen ungeheuren Urwald durchziehen, den sie allein zugänglich machen. Ich stieß auf neue Pflanzen, neue Tiere, neue Menschen. Meine Augen, seit sieben Jahren daran gewöhnt, die Berge sich in den Wolken verlieren zu sehen, konnten nicht davon ablassen, ständig den Horizont zu umgreifen, ohne dass sich ihnen ein anderes Hindernis in den Weg gestellt hätte als die Hügel des Pongo, die aus meinem Gesichtskreis bald verschwinden sollten. ${ }^{6}$

Wir befinden uns an einem semantischen Verdichtungsort der gesamten Reise: Eine neue Landschaft der Theorie tut sich auf. Und mit ihr eine ganze neue Welt. Der Reisende ist durch das bald schon verschwindende Eingangstor aus einer Welt des Dreidimensionalen in eine Welt der Zweidimensionalität eingetreten: Sein Auge vermag es nun, den gesamten Horizont lustvoll zu umgreifen und damit einem neuen Verstehen zuzuführen. eine neue Landschaft der Theorie eröffnet sich und mit ihr eine neue Epistemologie, die den Reisenden in das Gewirr der miteinander sich vernetzenden Flüsse wirft. Alles ist hier mit allem verbunden.

Der neue Flussabschnitt wird als neue Welt im emphatischen Sinne, mit neuen Pflanzen, Tieren und Menschen, apostrophiert, und präsentiert sich so dem europäischen Entdeckerblick als ein Kosmos, der zugleich von Europa und der andinen Welt Amerikas radikal getrennt ist. Amerika zeigt sich hier dem Auge des männlichen europäischen Betrachters gleichsam unverhüllt als das Andere Europas. Sein Auge trifft auf kein Hindernis mehr, eine Situation hermeneutischer Transparenz (in geradezu ekstatischer Erfahrung), die nicht wie später bei Rousseau dem Panoramablick vom Berg, sondern der Zweidimensionalität der Flusslandschaft und ihrer vielfachen Verbindungen euphorisch huldigt. Diese Passage steht nicht nur Jahrzehnte vor einer Ästhetisierung außereuropäischer Bergwelten; sie feiert geradezu den Wegfall der dritten Dimension als einen Weg hin zu einer größeren Einfachheit aller vom Menschen erkennbaren Bezüge.

Und zugleich präsentiert sich diese Flusslandschaft mit ihren vernetzten Flüssen als Labyrinth, in dessen Unermesslichkeit der Forscher eindringen und dessen Plan er dechiffrieren muss. Es ist eine Landschaft, in der alles mit allem

6 La Condamine, Charles-Marie de / Minguet, Hélène (Hg.): Voyage sur l'Amazone. Paris : La Découverte 1981, S. 60. 
zusammenhängt und sich in wechselseitigem Austausch befindet. Dabei wohnen wir einer Stilisierung des Ichs zur einsamen Forscherpersönlichkeit bei; doch der reale La Condamine wurde nicht nur von indianischen Ruderern und einem Führer, sondern auch von einem kolonialspanischen Gelehrten sowie später zeitweise hinzukommenden Mitreisenden begleitet, die im Bericht des französischen Reisenden freilich kaum einmal vorkommen. Vielmehr ist das erzählte Ich, das reisende Ich also, als Subjekt in einem direkten, unmittelbaren Austausch mit der es umgebenden Welt der Objekte. Nichts, keinerlei Vermittlungsinstanz, scheint hier die direkte Kommunikation des Forschers mit seinen Gegenständen ebenso der unbelebten wie vor allem auch der belebten Natur zu behindern.

Auf diese Weise schafft der literarische Reisebericht eine nicht weniger literarische Figur, die - auf dem Fluss der Amazonen und im freiwillig betretenen Labyrinth gefangen - an die Stelle mythischer Figuren der Antike tritt und an deren heroische Größe anknüpft. Das reisende Ich weiß sich in der Kontinuität dieser abendländischen Mythen, die von der Alten in die Neue Welt transportiert und anverwandelt wurden. Der Reisebericht wird dergestalt zu einer Echokammer, in welcher die verschiedenartigsten Verweise auf eine Welt hindeuten, die von den Mythen und Legenden anderer Völker durch und durch vollgesogen ist. So weiß sich der europäische Leser in einem vertrauten Gelände, begegnen ihm doch Landschaften und Gestalten, die ihm aus vielen (eigenen) Geschichten wohlbekannt und vertraut erscheinen. Die Reise in die Neue Welt wird gleichsam zur Nachlese der Alten: Alles ist uns auf eine unheimliche Art heimlich und augenzwinkernd vertraut.

Wir befinden uns in einem Text, der weit über das Dokumentarische hinausgeht und die schiere Materialität der Reise deutlich hinter sich lässt. Wer wagte da noch zu fragen, ob La Condamine dies alles so gesehen hat? Die bloße Augenzeugenschaft tritt unverkennbar in den Hintergrund und macht einer Konstellation Platz, in deren Mittelpunkt der eigentlich literarische Raum mit all seinen Verweisen und Vernetzungen steht. Die auf die außersprachliche Wirklichkeit verweisenden, von späteren Reisenden auch überprüften Landschaftselemente wie etwa der Pongo de Manseriche werden im Verbund mit spezifisch literarischen Techniken von Inszenierung und intertextuell potenzierter Semantisierung in eine unabschließbare oszillierende Bewegung gebracht, die nicht auf das Dokumentarische reduziert werden kann, sondern den friktionalen Status dieser Querung einer aquatischen Landschaft unterstreicht. Das Labyrinth ist tausendfach präsent.

Führen wir uns die Komplexität der Ich-Figur in diesem Reisebericht vor Augen. Das Ich ist in dieser Passage zugleich auf einer referentialisierbaren Ebene der Reisende und Naturforscher, der den oberen Marañón durchquert, 
auf einer historisch-literarischen Ebene der Erbe des Christoph Kolumbus, der einst vor der Mündung des Orinoco von einem Süßwassermeer gesprochen hatte, auf einer Ebene der griechischen Mythologie der Nachfolger des Theseus, diesen darin überbietend, dass er mit Hilfe seiner von ihm selbst gezeichneten Flusskarte den Faden finden wird, der ihn aus dem Labyrinth siegreich wieder herausführen kann, und schließlich auf einer psychoanalytischen Ebene jenes Ich, das die Immersion im Wasser wie eine Ekstase und die aquatische Landschaft der mer d'eau douce wie eine pränatale Wiedervereinigung mit der Mutter ekstatisch feiert. So wird diese Passage in mehrfacher Hinsicht kodiert und als Höhepunkt (sowie als Überschreitung einer Grenze) inszeniert. Eine Einebnung des Textes auf die erste, referentialisierbare Ebene würde dem friktionalen Textstatus bei weitem nicht gerecht. Denn die Polysemie des verdichteten semantischen Materials eröffnet viele parallele Lesarten und Lesemodi, die sich nicht auf eine dokumentarische Eindimensionalität zurückführen lassen, sondern eine Lust am Text entfalten, die sich aus dessen Viellogik und Vieldeutbarkeit speist.

Doch wenden wir uns einem zweiten Beispiel zu, um die Tragweite des reiseliterarischen Ortes des Höhepunktes in einem Reisebericht noch genauer erfassen zu können. Denn eine nicht weniger spektakuläre Inszenierung eines neuen Ortes und zugleich eines neuen Abschnitts des eigenen Reiseberichts findet sich in Louis-Antoine de Bougainvilles Voyage autour du monde, in welcher der Darstellung Tahitis eine besondere Bedeutung zukommt. Verlagern wir also den Schauplatz der Ereignisse vom Amazonas-Tiefland in die Weiten des Pazifik, genauer: der Südsee. Wir haben mit Bougainville in dessen Reisebericht eine weite Fläche des Meeres durchfahren und befinden uns, nach der wilden Umrundung des Kap Hoorn, auf einem Kurs in die Welt der Tropen. Die Annäherung an Tahiti, noch vor der Landung auf der Insel und der Erwähnung jenes Greises, der sich um die Europäer kaum zu kümmern scheint und zum intertextuellen Ansatzpunkt für Denis Diderots philosophisches Supplément au Voyage de Bougainville wurde, bietet dem Reiseschriftsteller Gelegenheit, ein anspielungsreiches Bild des angesteuerten Eilands zu entwerfen:

Der Anblick dieser wie ein Amphitheater geformten Küste bot uns das freundlichste Schauspiel. Obwohl die Berge eine große Höhe erreichen, zeigt doch der Fels nirgends seine aride Nacktheit: Alles ist von Wäldern bedeckt. Wir glaubten kaum unseren Augen, als wir einen Berg entdeckten, der bis hoch hinauf auf seine isolierte Spitze, welche die Höhe der Berge im Innern des Südteils der Insel erreicht, voller Bäume ist. [. . .] Von weitem hätte man diesen Berg für eine Pyramide von unermesslicher Höhe halten können, welche die Hand eines geschickten Bühnenbildners (décorateur) mit Blättern und Girlanden geschmückt hätte.

[...] 
Trotz aller Vorsichtsmaßnahmen, die wir treffen konnten, gelangte ein junges Mädchen an Bord, das sich auf dem Achterdeck in der Nähe einer der Luken platzierte, welche sich oberhalb des Spills befinden; diese Decksluke war geöffnet, um denen, die Dienst taten, Luft zuzuführen. Das Mädchen ließ achtlos seinen Lendenschurz, der es bedeckte, fallen und erschien vor aller Augen so, wie Venus sich dem phrygischen Schäfer zeigte. Es besaß deren himmlische Formen. Matrosen und Soldaten drängelten sich, um zur Luke zu gelangen, und nie wurde ein Spill mit solcher Heftigkeit betätigt. ${ }^{7}$

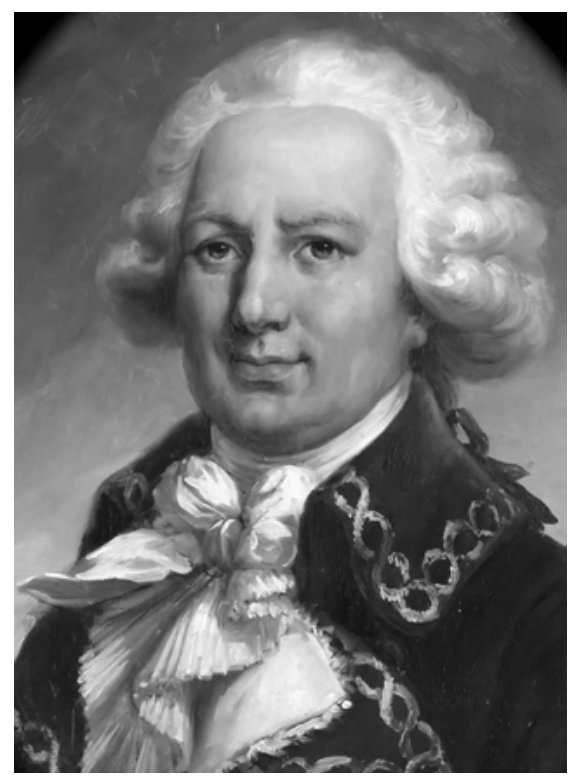

Abb. 31: Louis-Antoine de Bougainville (Paris, 1729 - ebenda, 1811).

Die Szenerie ist klug gewählt und präsentiert uns in einer ersten Bewegung so etwas wie ein Bühnenbild, auf dem sich die nachfolgende Szene abspielen wird. Dabei ist von Beginn an die kunstvolle Einfassung, die Artifizialität der Figuren wie ihrer Handlungen, deutlich akzentuiert. Die Literarizität der gesamten Szenerie wird uns explizit vor Augen geführt. Und es ist ein gutes, ein großes Stück Literatur, das für uns auf eine wohlbereitete Bühne gebracht und in Bewegung gesetzt wird.

7 Bougainville, Louis-Antoine de: Voyage autour du monde par le frégate du Roi 'La Boudeuse' et la flûte ' L'Étoile '. Paris: Gallimard 1982, S. 223 u. 226. 
Zweifellos vereint Louis-Antoine de Bougainville in seinem ausführlichen Panoramabild von See aus alle Bestandteile des locus amoenus, dessen unvermitteltes Erscheinen nach der mühsamen Schifffahrt und ihren monotonen Ausblicken auf das Meer auf den Leser überraschend wirken muss. Die karge Einöde der Meereswüste wird urplötzlich durch eine andere Landschaft ersetzt, die zunächst einmal in ihrer Dreidimensionalität aufgebaut wird, um den locus amoenus, den Lustort, überzeugend zu platzieren. Es ist eine Überraschung, die auf der Ebene des unmittelbaren Erlebens im Text verankert wird, hätten doch die Reisenden selbst ihren Augen kaum zu trauen gewagt. So wird auch das Lesepublikum damit konfrontiert, urplötzlich in einer ganz anderen, neuen Welt zu sein, die voller Überraschungen und voller Lüste ist.

Doch haben wir es hier nicht mit einer Szene zu tun, die letztlich alles andere als glaubwürdig ist? Anders als im Deutschen gewähren die Franzosen ihren Reisenden im Sprichwort ein gar weites Feld für Lügen aller Art: $A$ beau mentir qui vient de loin. Die Besonderheit dieser Passage ist darin zu erblicken, dass Bougainville an das kaum Glaubbare des Landschaftsbildes in ebenso paradoxer wie effizienter Weise nicht wie an anderen Stellen mit der Beglaubigungsstrategie naturwissenschaftlicher Messung und Beobachtung, sondern gerade mit der Betonung des Künstlerischen, Theatralischen, Artifiziellen antwortet. Nicht die Wissenschaften, sondern die Künste stecken den Referenzrahmen ab, innerhalb dessen sich die Szene ereignen kann und die geschilderten Ereignisse ihren Fortgang nehmen.

Nichts bleibt hier dem Zufall überlassen: Der Höhepunkt wird als Theatercoup in Szene gesetzt und verfehlt seine Wirkung nicht. Und es ist keine Geringere als Venus selbst, die sich den Matrosen in Gestalt eines unschuldigen tahitianischen Mädchens nähert - nur eben, dass die Göttin dies im Gegensatz zur jungen Tahitianerin keineswegs unschuldig, sondern in klarer Verführungsabsicht tat. Doch die Uhren auf Tahiti scheinen anders zu gehen: Nicht von ungefähr befinden wir uns - zumindest scheinbar - in einem Goldenen Zeitalter, wo Scham noch nicht der Schönheit ihr Erröten ins Gesicht schrieb. Den Reisenden bietet sich so gleichsam ein Naturschauspiel, in welchem sich die Natur der künstlerischen Mittel des Theaters bedient, um eine nackte Unschuld auf die Bühne zu bringen. Am Ende dieser ersten Darstellung Tahitis wird die Ebene des spectacle mit dem wirkungsvollen, stummen Auftritt eines Mädchens zum das gesamte Schauspiel erotisierenden Höhepunkt geführt. Es ist ein Mädchen und zugleich eine (abendländische) Göttin, die sich unseren Blicken so verführerisch zeigt. Die genderspezifische Rezeptionssituation braucht hier nicht eigens hervorgehoben zu werden.

An dieser Stelle greift das Schauspiel aus der Distanz auf die Nähe über: Der natürlichen, paradiesischen Schönheit des Landes entspricht die 
natürliche, schamlose Schönheit einer seiner Bewohnerinnen. Die Landschaft hat die Gestalt einer Frau angenommen: Das Motiv der schönen fremden Frau lässt grüßen. So ist das spectacle von der Natur auf den Menschen und von der Küste auf das Schiff der Reisenden übergesprungen; und an die Stelle des Landes ist dessen Verkörperung in Gestalt einer Frau getreten, die sich dem männlichen Blick darbietet. Weibliche Enthüllung und männliche Entdeckung gehen Hand in Hand: Im Reisebericht eines männlichen Reisenden wird der Entdeckerblick 'natürlich' männlich kodiert.

So wird der begehrliche Blick auf das verheißene Land zum begehrlichen Männerblick auf die paradieshaft unschuldig sich den Augen der Männer darbietende junge Frau. Diese doppelte Bewegung, welche das Amphitheater der Küste in der Tat nur zum Hintergrund, zum geschickt arrangierten Dekor des weiblichen Auftritts degradiert, führt zugleich die Zuschauerposition vor Augen, die nur durch eine dargebotene Öffnung, durch eine Luke, des Schauspiels voyeurgleich teilhaftig werden kann. Es ist die Bühne, und es ist der Guckkasten: Ärger entsteht nur dort, wo es ein Gedrängel um die besten Plätze gibt.

Auch hier haben wir es wie bei La Condamine mit einem guten, mit einem glänzenden Stück Literatur zu tun. Denn ähnlich ist die Funktion des an dieser Stelle abbrechenden, die Reize des Mädchens nicht weiter ausführenden Reiseberichts, so dass ein weiteres Überspringen von den ersten Zuschauern auf die zeitgenössische Leserschaft - und damit auch der immense Erfolg dieses Textes - vorprogrammiert ist. Louis-Antoine de Bougainville entwirft hier ein Theater der Bilder, in welchem das Mädchen nicht zu Wort kommt und so letztlich dem Reich der Natur zugeordnet bleibt; und doch ist es gerade dieses Stummbleiben, das es dem Erzähler erlaubt, die Körpersprache der schönen Unbekannten mit den Codes antiker Göttinnen, der Göttinnen der europäischen Antike, in Deckung zu bringen.

Auf diese Weise wird ein Spiel von Korrespondenzen zwischen Alter und Neuer Welt in Bewegung gesetzt, das Spiel einer friktionalen Literatur, deren Reisebewegungen sich jenseits diskursiver Grenzen keineswegs auf die außersprachliche Wirklichkeit beschränken. Dabei ist es nicht entscheidend, ob sich eine derartige Szenerie an Bord tatsächlich abgespielt hat: Entscheidend sind die literarischen Mittel, entscheidend ist die Allgegenwart der Fiktion. Daraus mag ein Gutteil der Faszinationskraft, die von Bougainvilles Reisebericht ausging, resultieren: und jene Südseetrunkenheit, mit welcher das zeitgenössische Publikum die Reiseberichte aus dem fernen Pazifik lustvoll genoss.

Es wäre - wie bereits betont - geradezu absurd, wollte man nach der Referentialität der letzten hier angeführten Passage aus Bougainvilles literarischem Reisebericht fragen. Längst hat die Textualität ihre Stellung eingenommen und das schlicht Dokumentarische einfach überwuchert. In kaum einem 
Reisebericht erscheinen die erwähnten reiseliterarischen Dimensionen in so dicht gedrängter Reihung wie in Bougainvilles literarisch ausgefeilter Darstellung von Tahiti. Die Zweidimensionalität des Meeres wird eindrucksvoll um die dritte Dimension der Höhenstufen erweitert, in einer gegenüber La Condamine umgekehrten Bewegung, die nicht den Übergang aus der Bergwelt zum 'Süßwassermeer', sondern jenen vom Meer zum Land unterstreicht. Die Reise in der Zeit schließt sich unmittelbar an, wird das Gesehene doch mit den abendländischen Hochkulturen (Pyramide, Venus und der phrygische Hirte, das neue Kythera, Bougainvilles nouvelle Cythère ${ }^{8}$ der tahitianischen Aphrodite) in Verbindung gebracht. Die Insel führt uns ihre Eigenzeitlichkeit vor Augen.

So tritt der Reisende selbst in eine Welt antiker Monumentalität ein, die sich - wie das Beispiel der Tahitianerin zeigt - vor seinen Augen in Bewegung zu setzen und zu leben beginnt, wobei sich unverkennbar Strukturen des Pygmalion-Mythos auf die Textebene durchpausen. Vor den Augen des Reisenden enthüllt sich - vielleicht ein letztes Mal - das Gemälde eines Goldenen Zeitalters, das die europäischen Reisenden zu genießen und gleichzeitig zu zerstören gekommen sind. Denn ihre Sinne wie ihre Sinnlichkeit beschränken sich nicht auf den Fernsinn des Auges; ihr Begreifen geht vielmehr in ein Greifen über, das zerstörerisch wirkt. Es ist nur noch eine Frage der Zeit, bis die Zeit des Goldenen Zeitalters für immer ausgelöscht sein wird.

Dieser vierten Dimension folgt in einer sich anschließenden Passage die Reise durch die sozialen Schichten der nur kurz besuchten tahitianischen Gesellschaft. Daraus entsteht so etwas wie eine erste ethnographische Skizze der sozialen Hierarchien auf Tahiti. Das gesamte Tableau aber ist eingebettet in die Dimensionen der Einbildungskraft und des Literarischen, die durch bekannte Anspielungen und Verweise eindrücklich auf die Imagination des Lesers einwirken und einen am abendländischen Kulturraum orientierten literarischen Raum tahitianisch re-kreieren. Aspekte einer genderspezifischen Analyse, aber auch des kulturellen Raumes auf Tahiti schließen sich an und deuten zumindest auf eine Behandlung der verschiedenen Dimensionen des Reiseberichts, wie sie von Bougainville geradezu mustergültig durchbuchstabiert werden. Die Vieldimensionalität Tahitis wird in den Vordergrund gerückt.

Im Zusammenlaufen dieser verschiedenen Dimensionen ergibt sich einer der am raffiniertesten gestalteten reiseliterarischen Orte, so dass der auf der referentiellen Ebene nur kurze Tahiti-Aufenthalt, der innerhalb des Reiseablaufs eine verschwindend kleine Etappe ausmachte, zum eigentlichen Höhepunkt

8 Ebda., S. 247. 
der Reise stilisiert werden konnte. Die Inselgruppe im Südpazifik wurde zur idealen Projektionsfläche für eine französische und insgesamt europäische Leserschaft, die ihre kühnsten Spekulationen als räumlich weit entfernte Wirklichkeit begriff. Tahiti wurde zu einem entfernten Kythera, von dem aus - wie wir sehen werden - auch kritische Blicke zurück auf Europa geworfen werden konnten. freilich aus einer Perspektive, welche die kulturellen Positionen der südpazifischen Kulturen nur als Vorwand und Bilderfläche für Reflexe benutzte, wie sie gut von Europäern aus nach Europa zurückgespiegelt werden konnten.

Louis-Antoine de Bougainvilles bis heute beliebter Reisebericht weist geradezu idealtypisch ein nicht fixierbares Oszillieren zwischen fiktionalem und diktionalem Pol auf. In diesem Kräftefeld liegen Spannung und Wirkkraft, die von diesem Reisebericht der europäischen Expansion in den pazifischen Raum ausgehen. Die überprüfbaren Koordinaten der Inselgruppe verbinden sich mit der Reise nach Kythera, die dokumentarische und die ästhetisch-literarische Funktion verbinden sich zu einer friktionalen Literatur, wie sie in dieser Eigenart wohl nur im 18. Jahrhundert so kunstvoll verfasst werden konnte. Dabei bot dieser Reisebericht zahlreiche Anknüpfungspunkte für die zeitgenössische europäische Philosophie, die sich in der Folge Tahitis in der Tat auch bemächtigte.

Halten wir an dieser Stelle als Zwischenergebnis einmal fest: Reiseliteratur erscheint in den angeführten Passagen dieses Kapitels, aber auch bei anderen AutorInnen und Texten in mehrfacher Hinsicht als eine Literatur in Bewegung, die sich durch ihre Vektorizität, aber auch durch ihre Vieldeutigkeit auszeichnet. Sie ist zugleich eine Literatur auf Reisen (Aphrodite auf Tahiti), eine Literatur, die den Leser reisen lässt, und schließlich eine Literatur, die sich an einem doppelten Ort des Schreibens - etwa in der Form des Reisetagebuchs und dessen Überarbeitung am Ursprungsort des Schriftstellers, in wessen Auftrag dieser auch immer auf Reisen ging - vollzieht. In der Tat wäre hier, nebenbei bemerkt, eine klassifizierende Unterscheidung von Reisen und Reiseschriftstellern möglich zwischen jenen Reisenden, die aus frei gewähltem Entschluss ohne Auftraggeber reisen (Alexander von Humboldt), Reisenden, die im Auftrag offizieller Institutionen reisen (La Condamine oder Bougainville, aber auch die britischen Lateinamerikareisenden des 19. Jahrhunderts), und schließlich Reisenden, die von ihren Reiseberichten leben wollen und in ihrem schriftstellerischen Visier ein anonymes Lesepublikum in ihrem Herkunftsland beziehungsweise in Europa anpeilen. Doch scheint es mir gleichwohl wesentlich sinnvoller zu sein, den literarischen Reisebericht nicht nach seinen jeweiligen Autorinnen und Autoren, sondern nach all jenen Aspekten zu analysieren, die mit der konkreten Textualität und mit der ästhetischen Verfasstheit der jeweiligen Berichte zu tun haben. Kehren wir daher folglich wieder zur Analyse der Reiseberichte selbst zurück. Oder vielmehr: Widmen wir uns in einem Exkurs einer Schrift, die ihrerseits zwar keine Reiseliteratur im engeren 
Sinne darstellt, durch ihr Gemachtsein aber reichlich Licht über die Reiseliteratur verbreitet. Machen wir also einen lustvollen Abstecher in die Philosophie.

Der französische Philosoph Denis Diderot hat sich der von Bougainville evozierten tahitianischen Thematik bemächtigt und fiktiv einen Supplementband zur Reise des französischen Gelehrten geschrieben, der als Supplément au Voyage de Bougainville bekannt wurde und $\mathrm{zu}$ den grundlegenden philosophischen Texten des französischen 18. Jahrhunderts gezählt werden darf. Es ist keine Frage, dass die Rede von der reichen Ausstattung Bougainvilles mit den lumières seiner Zeit, mit Fleiß und Ausdauer, Wissen und Naturgeschichte sehr zutreffend war, dass es aber in keinem Falle zutrifft, wenn behauptet wird, sein Stil sei einfach und eher einer Seemannssprache nahe gewesen. Das genaue Gegenteil ist der Fall. Es handelt sich vielmehr - wie wir bereits sahen - um eine sehr raffinierte Kompositionstechnik, die freilich an der Herausarbeitung bestimmter reiseliterarischer Höhepunkte und Orte ausgerichtet war. Damit aber blieb ein weites Feld für die philosophie.

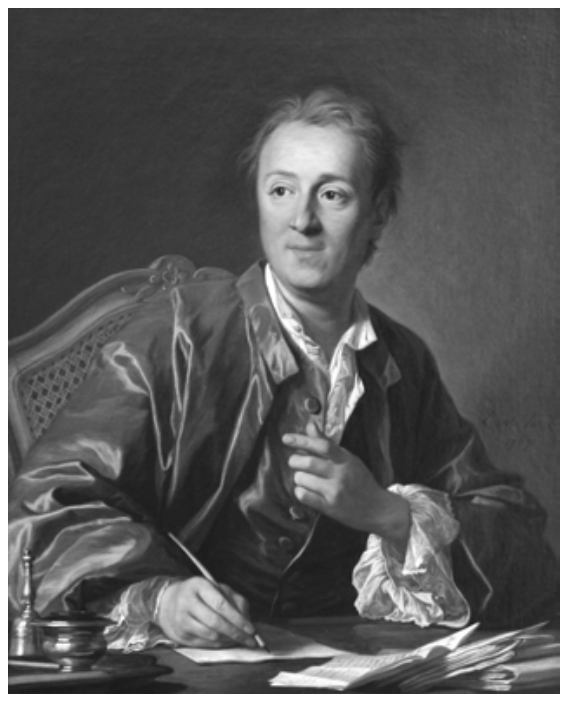

Abb. 32: Denis Diderot (Langres, 1713 Paris, 1784).

Beschäftigen wir uns in der gebotenen Kürze mit einigen Aspekten des Supplément zur Reise von Bougainville. Denis Diderot stellt bekanntlich im selbstverständlich fiktiven Dialog zwischen seinen Dialogpartnern A und B allerlei Überlegungen an - beziehungsweise legt sie seinen Gesprächspartnern in den Mund -, wie denn Menschen überhaupt auf die südpazifischen Archipele 
gekommen sein könnten und was an diesen so weit entfernten Orten denn ihre Zukunft sein werde. Er kann darüber ganz abstrakt philosophieren, ist sein Wissen doch nicht durch eine außereuropäische Erfahrung - geschweige denn Ortskenntnis - getrübt. Es ging ihm vielmehr um eine abstrakte philosophische Reflexion ausgehend von der Tatsache, dass er mit guten Gründen den TahitiTeil als den eigentlichen Höhepunkt des Reiseberichts von Bougainville erkannt hatte. Gestatten Sie mir also hierzu einen kleinen Exkurs.

Die gesamte von Bougainville ersonnene reiseliterarische Konstellation erwies sich als eine ideale Spielwiese für das Denken eines Philosophen der Aufklärung, dem es um die Entwicklung der Menschheit ging, der die universalisierten Prinzipien dieser Entwicklung aber allein aus Europa bezog und Phänomene wie etwa auch die Anthropophagie allein aus europäischer Perspektive betrachtete. Seitenhiebe Diderots gegen die Indianerreduktionen der Jesuiten in Paraguay - von wo die Jesuiten wenige Jahre zuvor ausgewiesen worden waren - konnte sich der ehemalige Jesuitenzögling Diderot freilich ebenso wenig verkneifen wie manche kleinere tagespolitische Anspielungen auf die politischen Verhältnisse in Frankreich. Warum um alles in der Welt kam der französische Philosoph auf die Besitzungen der Kirchenmänner in Paraguay zu sprechen? Die Jesuiten, so schloss Diderot bündig, wären ein Jahrhundert später schlicht nicht mehr auszuweisen gewesen, zu sehr wären sie dann zu einem Staat im Staate geworden, um noch aus selbigem entfernt werden zu können.

Und noch ein anderes Thema griff der französische Aufklärungsphilosoph dankbar auf. Neben den Jesuiten - einem obligaten Thema der Zeit mit Blick auf den Süden Amerikas - gab es natürlich auch ein weiteres Thema, das ebenfalls in jeder Berichterstattung und in jedem Reisebericht über Amerika auftauchen musste: die Frage nämlich, ob es in Patagonien nun Riesenmenschen gebe oder nicht. Diese Frage bewegte alle Zeitgenossen in Europa brennend - und kaum ein Kopf, der sich seit Amerigo Vespuccis Zeiten nicht dazu geäußert hätte. Im Anschluss an Bougainville konstatierte Diderot, dass es sehr wohl etwas größere und stark gebaute Menschen am Südzipfel des amerikanischen Kontinents gebe, dass es aber keineswegs Riesen seien, wie zuvor seit Beginn der Eroberung so oft behauptet worden war. Denis Diderot begnügte sich mit dem Hinweis, dass die Menschen eben allerorts mit dem „goût du merveilleux“9 auf die Welt kämen und alles um sie her übertrieben und nach ihrem Geschmack einfärbten. Damit aber nun zur tahitianischen

9 Diderot, Denis / Romeur, Anne-Laure (Hg.): Supplément au voyage de Bougainville. Paris: Petits Classiques Larousse 2017, S. 31 
Dimension seiner universalistischen Diskussion, die in seinem Supplément einen so breiten und vorrangigen Raum einnimmt.

Vor diesem Hintergrund ist es interessant und zugleich auch charakteristisch, dass Bougainville - wie es einst vor ihm Columbus tat - von seinem Besuch auf den weit entfernten tropischen Eilanden im Südpazifik einen veritablen Eingeborenen mit nach Hause, mit nach Frankreich nahm. Schon die Geste selbst ist ungeheuer kolonialistisch aufgeladen und wirkt noch abstoßender, wenn wir uns mit dem weiteren Verlauf des Schicksals dieses 'verpflanzten' Eingeborenen beschäftigen. ${ }^{10}$ Denn anders als bei Christoph Columbus wissen wir eine ganze Menge über diesen Besuch eines Südseeinsulaners in Europa. Hierzu mögen nur einige Hinweise genügen. Bougainville, der eigentlich Verantwortliche, kam nach dessen Aufenthalt in Frankreich für die Kosten der Rückführung Aotourous nach Tahiti auf; doch sollte dieser - wie wir heute wissen - seine Heimat nie mehr erreichen, sondern auf tragische Weise zugrunde gehen.

Wie dem auch immer sei: Rasch bildeten sich eine Vielzahl an Legenden und Mythen um diesen Südseeinsulaner zu Besuch in Europa; doch sollten wir einmal näher betrachten, wie Denis Diderot diese Thematik literarisch und philosophisch in seinem Supplément au Voyage de Bougainville behandelte. Dazu müssen wir kurz in den entsprechenden literarischen Dialog einsteigen.

Unser Dialogpartner B hat nicht nur Bougainvilles Reisebericht gelesen, er hat auch Aotourou in Frankreich getroffen, mit ihm gesprochen und berichtet uns nun darüber. Mir scheint es äußerst aufschlussreich zu sein, aus der Perspektive dieses fiktiven Augenzeugen einen Blick auf die Fremdwahrnehmung Europas zu werfen, handelt es sich doch hier nicht um einen fingierten Perser oder Marokkaner, sondern um einen veritablen Südseeinsulaner, der freilich auch in diesem Falle nicht selbst zu Wort kommt, sondern lediglich zu einem Beispiel für ein bewusstes Bauchrednertum verkommt. Denn klar: Wir hören nicht Aotourou, sondern die Stimme des französischen Philosophen:

Ich habe ihn gesehen, er hieß Aotourou. Das erste Stück Land das er sah, hielt er für die Heimat des Reisenden; sei es, weil man ihm die ganze Reise davon erzählt hat; sei es, dass er natürlich irregeleitet durch die scheinbar kleinen Entfernungen der Küsten die er bewohnt, wo der Himmel scheinbar am Horizont aufhört, die wirkliche Ausdehnung der Erde nicht kannte. Der ungezwungene Umgang mit Frauen war ihm so selbstverständlich, dass er sich auf die erste Europäerin die ihm begegnete, stürzte und dass er sich

10 Vgl. hierzu Gelz, Andreas: 'O Aotourou! (. . .) Que leur diras-tu de nous?' Die Figur des Aotourou in Diderots 'Supplément au Voyage de Bougainville' und die Grenzen interkulturellen Verstehens. In: Delon, Michel / Mondot, Jean (Hg.): L’Allemagne et la France des Lumières. Deutsche und französische aufklärung. Mélanges offerts à Jürgen Schlobach para ses élèves et amis. Paris: Champion 2003, S. 69-90. 
anschickte, ihr auf tahitische Art den Hof zu machen. Er langweilte sich unter uns. Da das tahitische Alphabet weder $b$, noch $c$, noch $d$, noch $f$, noch $g$, noch $q$, noch $x$, noch $y$, noch $z$ konnte er unsere Sprache, die seinen unbeweglichen Organen zu viele fremde Artikulationen und neue Laute bot, nie lernen. Er hörte nicht auf sich nach seiner Heimat $\mathrm{zu}$ sehnen und es wundert mich nicht. Die Reise von Bougainville ist die einzige die mir Lust auf eine andere Gegend als die meine gemacht hätte; bis zu dieser Lektüre dachte ich, dass man sich nirgends so wohl fühlte wie zu Hause und ich glaubte, es sei für alle Erdenbewohner gleich; eine natürliche Wirkung der Anziehungskraft der Heimaterde; eine Anziehungskraft, die von der Bequemlichkeit der man sich erfreut, herkommt und die wiederzufinden man anderswo nicht sicher sein kann. ${ }^{11}$

Es entbehrt nicht der Logik, dass der französische Philosoph sich zunächst mit der Sprache, mit dem Sprechen Aotourous beschäftigt, um dem 'Fremden' in einem zweiten Schritt gerade die Sprache gleichsam aus dem Mund nehmen zu können. Denn in dieser Passage werden der Südseeinsulaner und seine Möglichkeiten des Sprechens ausschließlich negativ gekennzeichnet: Seine Sprache erscheint nur in ihren negativen Abweichungen von der Norm der französischen Sprache und damit als defizitär. Was hier im Modus der Deskription, des Deskriptiven erscheint, ist in Wirklichkeit eine gelassene Abqualifizierung zu einer linguistischen Unfähigkeit, sich der Norm gerecht ausdrücken zu können.

In einem dritten Schritt geht es dann um Aotourous kognitive Fähigkeiten und seine Wissensstände. Auch sie werden negativ konturiert. Aotourou weiß zunächst mit den Distanzen nichts anzufangen, verfügt auch nicht über die Informationen, die ihm erlauben würden, die Größe der Erdkugel wirklich einzuschätzen und daraus die Lage seines Heimat-Eilandes $\mathrm{zu}$ bestimmen. Dies wiederum ist an die Sprache zurückgekoppelt: Denn des Weiteren verfügt er auch nicht über die sprachlichen und somit kognitiven Voraussetzungen, da seine eigene Sprache, das Tahitianische - von dem niemand zum damaligen Zeitpunkt viel wissen konnte -, über eine Vielzahl von Lücken, von negativen Ausfällen im Vergleich zum Französischen und zu den europäischen Sprachen überhaupt gekennzeichnet ist, so dass er sich die Vorstellungswelt der Europäer erst gar nicht aneignen kann. Es geht nicht darum, welche Sicht von Europa und seinen Bewohnern der Tahitianer entwickelt, sondern dass er nicht in der Lage ist, sich auch nur die richtigen Fragen zu stellen.

So sind allerlei Missverständnisse an der Tagesordnung. Denn auch die kulturellen Sitten und Gebräuche im Europa der Aufklärung sind dem Fremden völlig unbekannt: Er überträgt die tahitianischen Vorstellungen unmittelbar auf den europäischen Kontext, indem er sogleich die tahitianische Sitte körperlicher Liebesbezeugung - natürlich eine europäische Vorstellung vom 'Anderen' - der

11 Diderot, Supplément, S. 32. 
ersten Europäerin anbietet, die auf ihn zukommt, so dass er nicht in der Lage zu sein scheint, die neuen kulturellen Kontexte überhaupt zu erfassen, denen zufolge in Europa die freie, unmittelbar und spontan ausgeübte Liebesbezeugung mit allerlei Tabuisierungen verbunden ist. Aber natürlich: wir haben es hier nur mit einer Fiktion des Fremden, des Anderen zu tun - ganz zum Nutzen und Gebrauch einer Aufklärungsphilosophie nach europäischem Geschmack.

Bemerkenswert ist freilich, dass der Dialogpartner B unmittelbar nach diesen negativen Charakteristika und der Fremd-Schreibung des Pazifikbewohners für sich selbst durchaus den Anspruch erhebt, gerne einmal diese in jeglicher Hinsicht so weit entfernten Weltgegenden besuchen $\mathrm{zu}$ wollen, habe ihm der literarisch so gelungene Reisebericht von Louis-Antoine de Bougainville doch erstmals diesen Gedanken an eine Besichtigung Tahitis eingegeben. Was aber erwartet oder erhofft sich der Franzose von einem derartigen Aufenthalt?

Die Idee kommt ihm ganz offensichtlich vor dem Hintergrund der eigenen Selbsteinschätzung, der zufolge die Europäer auf einen Aufenthalt auf Tahiti aufgrund ihrer Überlegenheit weit besser vorbereitet sind als die Tahitianer auf einen Aufenthalt in Europa, verfügen sie doch zweifellos über bessere sprachliche und kognitive Voraussetzungen. Es ist also nicht allein die technische und technologische Überlegenheit europäischer Schiffe und Seemannskunst, welche in der zweiten Phase beschleunigter Globalisierung den Europäer zum Reisenden, zum Weltreisenden werden lässt, der seine Ziele weltumspannend auszuwählen vermag.

Aber wer weiß: Vielleicht übertragen die Europäer ebenso wie der hier dargestellte fingierte (und reale) Tahitianer nur ihre eigenen Vorstellungen auf ein fremdes Land, auf eine fremde Weltgegend, und erleben dadurch ebenso eine interkulturelle Überraschung, die möglicherweise nicht geringer ausfallen könnte als jene des Tahitianers, dessen ungestümes Liebesverlangen, das sich auf jegliches heterosexuelle Objekt zu projizieren scheint, ins Leere ging. Mit einem kleinen Unterschied freilich: Denn die Europäer sind nicht nur in der Lage, in der zweiten Phase beschleunigter Globalisierung ihnen noch unbekannte Inseln und Inselwelten im Pazifik kontrolliert und wiederholbar anzulaufen, sondern besitzen auch die logistische Fähigkeit, die ihnen fremde Zivilisation nicht nur in ihrer weiteren Entwicklung zu bedrohen, sondern auf grundlegende Weise dem Untergang $\mathrm{zu}$ weihen und gänzlich zu zerstören. Es ist das Bewusstsein dieser Macht, das den ganzen Unterschied macht zwischen Europa und den fremden Welten: Nicht zuletzt hierauf gründet sich das Überlegenheitsgefühl der europäischen Mächte Frankreich und England, die miteinander im Wettlauf um den Erhalt dieser Inselgruppen wie auch anderer Gebiete im fernen Pazifik stehen.

Diese machtpolitischen Verhältnisse bilden den Hintergrund nicht allein für den Dialog der Rahmenerzählung, sondern auch für die Teile 2, 3 und 4 des 
Supplément, welche recht ausführlich eine Art des interkulturellen Vergleichs mitbeinhalten. Dieser Kulturvergleich ist aber unverkennbar und deutlich abgesetzt von der Rahmenerzählung, in welcher es um den realen, den konkreten (und natürlich fiktionalen) Tahitianer Aotourou geht. Der Orou der Binnenerzählung und der internen Textteile hingegen wird ein wahrer Ausbund an philosophischen Einsichten und Überlegungen sein, der es den Vertretern der europäischen Zivilisation sehr schwer - wenn nicht unmöglich - machen wird, argumentativ die eigene Zivilisation zu verteidigen und vor der Vielzahl an Angriffspunkten zu 'retten'. Damit dreht Diderot gleichsam den Spieß seiner interkulturellen Argumentation um: Nicht das reale, sondern das fingierte Tahiti wird zum fernen Spiegel, in welchem sich Europa selbst betrachtet und sich den (eigenen) Spiegel vorhält. Hier greift die literarische und philosophische Fiktion ein über ein fingiertes Fremdbild, das dem 'Anderen' schlicht in den Mund gelegt wird und es dem Philosophen zugleich erlaubt, scheinbar eine kritische Außenperspektive zur europäischen Zivilisation aufzubauen.

Nicht zuletzt auch an diesem Konstruktionsprinzip wird deutlich: Denis Diderot ging es nicht um eine wie auch immer geartete Wertschätzung einer konkreten außereuropäischen Kultur, sondern um eine generelle, gleichsam philosophische Fragestellung unabhängig von einer realen interkulturellen Kommunikationssituation. Denn es ist eine ebenso imaginierte wie imaginäre Außerhalbbefindlichkeit, die hier mit der europäischen Zivilisation und gleichzeitig gegen die europäische Zivilisation ins Feld geführt wird, um diese letztlich einer stärkenden Kritik zu unterziehen.

Dabei ist es im Übrigen aufschlussreich, dass Dialogpartner B der Meinung ist, Aotourou werde nur wenig zuhause über seine Erfahrungen in Europa berichten und seinen Landsleuten mitteilen können - und überdies werde man ihm nicht glauben, seine Sichtweisen Europas für erflunkert halten. Dies erinnert recht stark an das Platon'sche Höhlengleichnis, wo der Mensch, der die Höhle kurzzeitig zu verlassen und die Sonne direkt zu sehen imstande war, wieder zu seinen ehemaligen Mitgefangenen zurückkehrt, welche die Dinge nur als Schatten an der Höhlenwand und niemals im direkten Sonnenlicht kennen. Doch was nutzt es dem Menschen, dass er von der Welt an der Oberfläche berichtet? Denn seine Mitgefangenen sind ebenso wenig bereit, ihm Glauben zu schenken, ja bedrohen ihn sogar damit, ihn aufgrund seiner gefährlichen Lügen und Unwahrheiten für immer zum Schweigen zu bringen. Die Wahrheit allein, wird sie von niemandem geglaubt, macht nicht frei, sondern gefährdet ihren Überbringer, der sich nicht erklären kann, wie er in eine solche Lage kommen konnte. 'Die Wahrheit wird euch frei machen' - jener Denkspruch (joh 8, 32), der am Kollegiengebäude I der Albert-Ludwigs-Universität zu Freiburg im Breisgau prangt und als Universitätsdevise zu verstehen ist, ist mit Vorsicht 
zu genießen: Denn wahr ist nur, was (zu einem bestimmten Zeitpunkt) auch geglaubt wird. Und doch, so bliebe hinzuzufügen, ist die Wahrheit zu ergründen noch immer die Aufgabe von Wissenschaft, genauer: die Erkundung von Wahrheiten. Dann aber gehen Wahrheit und Freiheit Hand in Hand.

Doch kehren wir zu Diderot und ins 18. Jahrhundert zurück. Denn in der Tat wird sich Diderot etwas später in seinem Supplément au Voyage de Bougainville noch verschiedentlich auf die cavernes und damit implizit auch auf Platons Höhlengleichnis beziehen. Aotourou aber, soviel steht für B fest, könne nicht viel erklären: Er besitze in seiner Sprache ganz einfach keine Begriffe dafür und keine Worte, um seinen Mit-Insulanern alles zu erklären. Wir sehen: Für Diderot ist die Sprache die zentrale Fähigkeit und Befähigung des Menschen, ja mehr noch: Sie macht sein eigentliches Menschsein aus.

Kommen wir nun zum eigentlichen Supplément zum Reisebericht Bougainvilles, auf das uns der Dialog der beiden Männer nur vorbereiten sollte, ein Reisebericht, der bei B auf dem Tisch liegt und in der Folge vorgestellt und diskutiert wird. Es folgt also nun die nachfolgende gemeinsame Lektüre der beiden Dialogpartner, welche die Zeit füllen soll, bis draußen der nicht ganz zufällige Nebel - der freilich am Ende symbolhafterweise keineswegs verschwunden sein wird - sich gelichtet hat. Dergestalt folgt also der zweite Teil des Supplément, der die Überschrift 'Les adieux du vieillard' und zugleich einen ganz anderen Charakter trägt. Denn hier lässt Diderot seiner Imagination freien Lauf.

In 'Les adieux du vieillard' wird uns ein Greis vorgestellt, der in seiner nun folgenden Rede oder harangue ein durchweg negatives Bild der Europäer, ihrer Zivilisation und ihres Verhaltens zeichnet. Die Gattung der harangue ist sicherlich eine der Stärken der Feder Diderots, die er auch vor allem in der dritten Auflage von Raynals Histoire des deux Indes glänzend zur Geltung brachte. Dabei ist ein Teil der Schmährede des alten Mannes, dass die Europäer schon sehr bald und auch künftig das Glück, das zweifellos auf der Insel Tahiti herrsche, bedrohen und zugrunde richten würden. Für den weisen alten Mann steht es außer Frage, dass von den europäischen 'Besuchern' eine solche Wirkung zwangsläufig ausgehen müsse: Sie tragen gleichsam den Keim der Zerstörung dessen, was sie bewundern - ganz im Sinne von Claude Lévi-Strauss‘ Tristes Tropiques - in und mit sich.

Wir haben es folglich mit einem zivilisationskritischen Teil des Supplément au Voyage de Bougainville zu tun, wobei als Sprachrohr sozusagen ein weiser Mann, ein Ältester dient, ein Verfahren, das uns nicht nur in der abendländischen Kulturtradition seit langen Zeiträumen bekannt ist. Der weise, alte Mann ist eine patriarchalische Chiffre vieler Kulturen. Nicht über Bougainvilles Abreise, so ruft der Greis seinen Mit-Tahitianern zu, sondern über Bougainvilles Ankunft 
sollten die Bewohner Tahitis weinen, seien doch damit die schönen Tage der Inselwelt im Südpazifik ein für alle Mal gezählt. Nichts bleibe so, wie es war.

Denn eines schönen Tages würden diese Europäer mit ihren Schiffen zurückkehren und ihre Bösartigkeit sowie ihre kolonialistische Unterjochung aller nicht-europäischen Kulturen offen zeigen. Bald schon würden die Masken der Franzosen fallen. Die Wendung des Greises an Bougainville apostrophiert diesen als „chef des brigands“, mithin als einen Räuberhauptmann, der den Tahitianern erstmals die scharfe Unterscheidung zwischen Mein und Dein und damit die Frage des privaten Eigentums und der Besitzrechte beizubringen versucht habe. Dies aber sei der Anfang vom Untergang der tahitianischen Zivilisation, des anhaltenden Lebensglückes der Bewohner dieser Inselwelt.

Der Greis verweist nicht zu Unrecht auf jenes kleine Metallschild, das die Europäer hier zurückließen und das besagt, dass Bougainville und seine Mannschaft im Namen des Königs von Frankreich für ihre französische Heimat Besitz von der Inselgruppe ergriffen hätten. Und der alte Mann fährt fort und fragt rhetorisch geschickt, wie denn die Franzosen reagieren würden, käme bei ihnen eine Gruppe von Tahitianern an Land, um sofort von selbigem Besitz zu ergreifen und dies auf einem Stein schriftlich festzuhalten. Wer gebe den 'Besuchern' das Recht auf legalen 'Besitz' von Gütern, die sie gerade erst erblickt hätten?

Dabei macht sich der Greis über die inhärenten Widersprüche im Kolonialprojekt der Franzosen lustig, indem er deren Doppelbödigkeit an Maß und Begriff aufscheinen lässt. Zwar habe sich Bougainville über den Diebstahl kleinster, unnützer Habseligkeiten von seinem Schiff fürchterlich aufgeregt, selbst aber ein ganzes Land gestohlen, eine Argumentation, die nun unverhohlen antikolonialistisch wird und politischen Sprengstoff in sich trägt. Kein Zweifel: In diesen harangues läuft Diderot zu jener großen Form auf, wie er sie später auch in der von Guillaume-Thomas Raynal veröffentlichten Kolonialenzyklopädie der Histoire des deux Indes machtvoll unter Beweis stellen sollte. Rhetorisch brillant und argumentativ raffiniert führt der Greis vor, welches Unheil die eingedrungenen Europäer alsbald auf Tahiti anrichten würden, und wie weit das von ihnen gestiftete Unglück schon in die zwischenmenschlichen Beziehungen zwischen Tahitianerinnen und Tahitianern eingedrungen sei. Alles werde zugrunde gehen: Leben und Lieben würden sich ein für alle Mal auf den Inseln unumkehrbar verändern.

Es folgt dann ein eingeschalteter Dialog von A und B, welcher sozusagen die Rahmenhandlung wieder ins Bewusstsein des Lesers zurückholt und der den narrativ-diskursiven Kitt bildet, um die einzelnen Bestandteile des Supplément literarisch zusammenzuhalten. Ich kann hierbei nicht auf eine Reihe recht interessanter Details eingehen wie etwa auf jene Hinweise, es handle sich um eine harangue, die zunächst ins Spanische und von dort ins Französische übertragen worden sei, so dass allerlei europäisches Gedankengut miteingeflossen ist. Selbstverständlich 
haben wir es hier mit einem europäischen Räsonnement zu tun, das sich gegen den europäischen Kolonialismus richtet, weil dieser sich aller nicht-europäischen Länder bemächtige, nur um den eigenen Vorteil zu mehren.

Das ist zum einen recht geschickt auf die eigenen Beschränkungen der Perspektive Denis Diderots und dessen eingeschränkten Kenntnisstand bezogen, macht zum anderen aber auch auf die Bedingungen und den Preis interkultureller Kommunikation aufmerksam, der im Übrigen ganz wesentlich die Frage der Übersetzung und Übersetzbarkeit betrifft. Was auf diesen Dialog zwischen A und B nun folgt, ist nun nicht mehr als Monolog, als Rede, als Beschuldigungs- und Schmährede, vorgetragen, sondern wiederum in der Form eines Dialoges organisiert, wobei nun die Gesprächspartner den beiden unterschiedlichen beteiligten Kulturen entstammen, zu deren Sprachrohren und Vertretern sie werden. Damit wird die Rede des Greises aus der Monolog- in die Dialogform überführt, um sie gleichsam an einer konkreten Auseinandersetzung beispielhaft vorzuführen. Sehen wir uns dies einmal genauer an.

Es geht um den Dialog zwischen einem Schiffsgeistlichen, dem aumônier, und dem des Spanischen Kundigen Orou, der schon von seinem Namen her nicht mit Aotourou verwechselt werden darf. Im angeregten und bisweilen pfiffigen Dialog wird die Validität und Legitimität bestimmter kultureller Konzepte und Vorstellungen erprobt, wobei natürlich die beteiligte andere Kultur im europäischen Diskurs nicht selbst zu Wort kommt, sondern fingiert wird, hatte doch - wie wir schon wissen - der reale Aotourou schlichtweg nichts zu sagen. Dies ist übrigens ein interessantes Beispiel, wie man ganz elegant verhindern kann, dass der Andere und das Andere wirklich zu Wort kommen und einen eigenen Platz im Dialog beanspruchen. Auch dies ist eine Form des europäischen Kolonialismus - und ein solches diskursives Bauchrednertum hat eine sehr lange Tradition, ja lässt sich bis in unsere Tage verfolgen.

Der honorige Schiffsgeistliche war, wie alle anderen Seeleute auch, auf eine Hütte der Tahitianer verteilt worden, von deren Bewohnern ihm Gastgeschenke gemacht wurden, die unter anderem auch - und dies ist aus den Schiffstagebüchern verbrieft - Liebesdienste beinhalteten. Eine für unseren Schiffsgeistlichen unangenehme Situation, denn wie sollte er sich als katholischer Geistlicher nun verhalten? An dieser Problematik entzündet sich eine der grundlegenden Fragestellungen in der Rezeption von Bougainvilles Reisebericht wie im Diderot'schen Supplément zu dieser Reise: Wie kann es denn sein, dass körperliche Liebe, die im Abendland so ungeheuer stark tabuisiert und in gesellschaftliche Konventionen eingekleidet wurde, auf diesen Südseeinseln so ganz einfach, spontan und offen - wie es den Franzosen schien - praktiziert werden konnte. Kein Wunder: Tahiti erschien in den Augen der Franzosen und ihrer Zeitgenossen zuhause als ein Reich der unbegrenzten Liebe. Und noch in den Hollywood-Verfilmungen 
des 20. Jahrhunderts ist in den eher prüden Vereinigten Staaten eine Menge Knisterstoff diesbezüglich vorhanden.

Es war nicht schwer für Diderot, aus diesen Geschlechterverhältnissen eine zutiefst philosophische Problematik mit allerlei begrüßenswerten erotischen Zwischentönen zu machen. Und das tat der französische Philosoph dann auch. Denn diese Frage faszinierte nicht nur Diderot, sondern alle Zeitgenossen in Europa und warf ein Licht auf die Relativität kultureller Vorstellungen vom menschlichen Körper und seinen Praktiken, ohne dabei sogleich zu einem billigen Kulturrelativismus zu führen. Auch Diderot selbst war von einem solchen meilenweit entfernt.

Doch wird die Arbitrarität kultureller Vorstellungen auch und gerade im Abendland oder in dem, was man auch als den Westen bezeichnen könnte, deutlich, habe man sich doch so sehr vom Naturrecht und vom natürlichen Verhalten des Menschen entfernt, dass man selbst die körperliche Lust nur noch unter schlimmen Gewissensbissen genießen könne. Was blieb dann übrig? Und wie sollte sich ein katholischer Geistlicher angesichts derartiger Usancen untadelig verhalten? Sollte er streng auf europäischen Sitten beharren oder das Gastgeschenk freudig annehmen?

Er seufzt und tut. So ruft der arme Schiffskaplan, der in der Folge die Liebesdienste der jüngsten, der mittleren und der ältesten Tochter Orous sowie letztendlich auch von dessen Frau in Anspruch nehmen muss und nimmt, immer wieder in seinen Liebesnächten aus: „Mais ma religion, mais mon état!“ Damit ist freilich nicht der Naturzustand, sondern gerade der Gesellschaftszustand gemeint; und dieser wird in einem Kontext und Zusammenhang problematisch, der - so die Erzählerfigur - um ein Vielfaches jenem der Natur näher steht als die europäischen Gesellschaften und Zivilisationen es jemals taten. Unser katholischer Geistlicher wird schlicht in den Naturzustand überführt und in seiner Nacktheit der Fleischeslust überantwortet. Honni soit qui mal y pense!

Übrigens ist es auch bemerkenswert, dass in diesem Zusammenhang auch von der Präsenz einer Frau an Bord berichtet wird, die in Männerkleidern als vermeintlich männlicher Domestik unbedingt eine Weltreise unternehmen wollte, nun aber von den Tahitianern als Frau entlarvt und ihrer eigenen Form von civilité zugeführt wird. Sie sehen: Der Segen der Liebe wird reichlich über alle Figuren ausgegossen. Und verkleidete Frauen an Bord von Segelschiffen? Das war gar nicht so sehr an den Haaren herbeigezogen, wie es scheinen mag: Die Geschlechterzwänge in Europa ließen manche Frau erfinderisch werden und zum weltreisenden Mann mutieren.

Dann führt Diderot in die Erörterungen ein rationales biopolitisches Argument ein. Ich kann und will der Frage nach der freien Liebe an dieser Stelle freilich nicht ausführlich nachgehen sowie die damit verbundene Argumentation erörtern, den Tahitianern, die ihre Bevölkerung hätten vermehren wollen, sei 
es ganz zielstrebig nur darum gegangen, durch die Einsammlung des europäischen Samens die eigene Bevölkerung zu vermehren und zugleich auch mit intelligenten (sic) Exemplaren der menschlichen Spezies zu bereichern. Es ist ein Argument, das gleichsam die kulturelle Dimension ausblendet, um einen biologischen, auf biologische Diversifizierung abstellenden Gedanken einzuführen und entsprechend stark zu machen. Ich will hier auch nicht der Frage nach dem Gottesbegriff nachgehen, die ebenfalls abgeleitet von den Problemen des Schiffsgeistlichen in seinem Verhältnis zu den der Kirche geschuldeten Pflichten, auch in Form der Keuschheit, thematisiert wird. All dies sind aufschlussreiche biopolitisch-theologisch-philosophische Fragen, auf die ich Sie nur hinweisen kann, ohne diesen Aspekten doch detailliert nachzugehen.

Wichtig ist für uns im Kontext unserer Vorlesung aber vor allem, dass aus dem interkulturellen Dialog erst jene Fragen entwickelt werden, welche die europäische Aufklärung als einen Prozess zwischen zwei Welten erkennen lässt. Dass dabei der eigenen abendländischen Welt eine andere, nicht-abendländische gegenübergestellt wird, die doppelt durch die Schiffstagebücher und deren apokryphe Bearbeitung verstellt und deplatziert, fingiert und kulturell in ein Anderes projiziert wurde, soll uns dabei nicht stören, haben wir uns mit diesem Tatbestand doch bereits mehrfach vertraut gemacht. Doch die Erfahrung wie die Projektion des Außereuropäischen werden - wie schon in Montesquieus Lettres persanes oder in Cadalsos Cartas marruecas - zum eigentlichen Motor oder zumindest doch zum philosophischen Treibstoff, der die gesamte Geschichte in Gang hält. Erst die Stilisierung eines Anderen zu einem Anderen erlaubt es, das vermeintlich eigene neu zu perspektivieren und von diesem Anderen, erst einmal fein säuberlich konstruiert, abzuscheiden.

Hier, so scheint mir, liegt die eigentliche Würze dieser Bearbeitung eines Reiseberichts, eine Rezeption, die durch viele andere Texte, unter ihnen Georg Forsters Reise um die Welt mit ihrer wiederum eigenen, aber von Bougainville keineswegs unabhängigen Darstellung Tahitis weitergeführt werden könnte. Es ist hier nicht der Ort, in unserem Exkurs, der langsam schon zur Exkursion wird, diese hochinteressante Fragestellung weiter $\mathrm{zu}$ verfolgen. Ich kann der Versuchung allerdings nicht widerstehen, Ihnen an dieser Stelle zumindest einen kleinen Einblick in Georg Forsters Reisebericht zu geben, wo denn der Aufenthalt auf Tahiti mit den folgenden Worten beginnt: „Ein Morgen war's, schöner hat ihn schwerlich je ein Dichter beschrieben“"12 - ein fürwahr trefflicher Auftakt für eine Schilderung, die

12 Forster, Georg: Reise um die Welt: illustriert von eigener Hand. Mit einem biographischen Essay von Klaus Harpprecht und einem Nachwort von Frank Vorpahl. Frankfurt a. M.: Eichborn 2007, S. 177. 
viel zur Südseetrunkenheit des europäischen Publikums beitragen sollte. Verweilen wir also kurz bei Georg Forster, dem am weitesten gereisten der großen Schriftsteller des deutschen 18. Jahrhunderts (vgl. Abb. 68: Porträt des Georg Forster).

Ich wähle dabei eine Passage, die sich im Übrigen im vielfachen Sinne einbauen lässt in die interkulturellen Diskurse, die im 18. Jahrhundert von Europa aus auf die gesamte Welt projiziert wurden. Sie werden dies gleich bemerken. Georg Forster schildert eine Situation, in der gerade James Cook und seine Offiziere das Schiff verlassen haben und damit die Matrosen alleine an Bord, sozusagen alleine $\mathrm{zu}$ Hause sind. Im Grunde eine Routinesituation, die keinem britischen Seemann Angst machen müsste. Doch was in solchen Fällen einer sturmfreien Bude auf dem schönen Tahiti passieren kann, wird im Folgenden eindringlich aufgezeigt:

Während dieser Zeit war das Schiff mit einer Menge von Canots umringt, die außer allerhand Kräuterwerk, auch große Quantitäten einländischen Zeugs verhandelten. So gar auf den verdecken wimmelte es von Indianern, und unter selbigen gab es verschiedene Frauenspersonen, die sich ohne Schwierigkeiten den Wünschen unsrer Matrosen überließen. Einige von denen, die dieses Gewerbe trieben, mochten kaum neun oder zehn Jahr alt seyn und hatten noch nicht das geringste Zeichen der Mannbarkeit an sich. So frühzeitige Ausschweifungen scheinen einen sehr hohen Grad von Wollust anzudeuten und müssen im Ganzen allerdings Einfluß auf die Nation haben. Die natürlichste Folge davon, die mir auch sogleich in die Augen fiel, bestand darin, daß das gemeine Volk, zu welchem alle diese liederlichen Weibsbilder gehören, durchgehends von kleiner Statur war. Nur wenige einzelne Leute aus demselben, waren von mehr als mittlerer Größe; die übrigen waren alle darunter - ein Beweis, daß die Meynung des Grafen Büffon, über die frühzeitige Vermischung beyder Geschlechter (S. dessen Hist. naturelle) sehr gegründet ist. Sie hatten unregelmäßige, gemeine Gesichtszüge, aber schöne, große Augen, die durchgehends sehr lebhaft waren; nächst diesen ersetzte auch ein ungezwungenes Lächeln und ein beständiges Bemühen zu gefallen, den Mangel der Schönheit so vollkommen, daß unsre Matrosen ganz von ihnen bezaubert waren und auf die leichtsinnigste Weise von der Welt, Hemder und Kleider weggaben, um sich diesen neuen Mätressen gefällig zu bezeigen. Die ungekünstelte Einfalt der Landes-Tracht, die den wohlgebildeten Busen und schöne Arme und Hände unbedeckt ließ, mochte freylich das ihrige beytragen, unsre Leute in Flammen zu setzen; und der Anblick verschiedner solcher Nymphen, davon die eine in dieser, jene in einer andern verführerischen Positur behend um das Schiff herschwammen, so nackt als die Natur sie gebildet hatte, war allerdings mehr denn hinreichend, das bischen Vernunft ganz zu blenden, das ein Matrose zu Beherrschung der Leidenschaften etwa noch übrig haben mag. ${ }^{13}$

Es ist zweifellos aufschlussreich, dass Georg Forster hier auf Tahiti von Indianern spricht. Dass es sich hier um einen europäisch-kolonialistischen Diskurs handelt, wäre uns freilich auch ohne diese Markierung aufgefallen. Zusätzlich

13 Ebda., S. $181 \mathrm{f}$. 
zur patriarchalischen Einfärbung zeigt dies nicht zuletzt, wie sehr die Eindrücke des Umgangs mit außereuropäischen Völkern sich vermischen können und innerhalb der Kategorie des ‘Anderen' nicht mehr nach Differenzen und Differenzierungen lange gesucht wird.

Doch konzentrieren wir uns auf den Inhalt dieses Auszugs aus Forsters Reise um die Welt, dem inoffiziellen Bericht von der zweiten Weltumsegelung des James Cook im Auftrag der britischen Krone. Deutlich wird in dieser Passage nicht nur, dass die sozialen Unterschiede und auch das Klassenbewusstsein des Reiseschriftstellers eine klare Abgrenzung und Ausgrenzung der Matrosen vornimmt, die gleichsam deklassiert und aus dem Reich der aufgeklärten Vernunft ausgebürgert werden, während der Schriftsteller selbst seine Sinne so sehr zusammenzunehmen vermag, dass er diese Szenen nicht nur distanziert schildern kann, weil er den Reizen der Schönen nicht erliegt, sondern darüber hinaus auch eine Vielzahl kritischer Bemerkungen, aber auch Vergleiche mit antiken Vorbildern wie den Nymphen anstellen und einbringen kann. Hier gibt es noch mehr.

Die jungen Tahitianerinnen erscheinen in einer sehr ambivalenten Weise als Nymphen und als Prostituierte, als Nymphomaninnen und als Unschuldige, als Hässliche von kleiner Statur und als Schöne mit wohlgestalteten Proportionen, so dass der gesamten Passage ein hoher Grad an Ambivalenz zukommt. Ambivalent ist dabei die Position des Reiseschriftstellers nicht zuletzt selbst, gerät ihm die ganze Passage doch schlussendlich zu einer Lobpreisung auf die Schönheit der jungen Frauen Tahitis. Zweifellos ist auch in diesen Ausführungen Tahiti der Ort der Lüste, ja der Wollüste, welche freilich zugleich in einen biopolitischen, medizinisch-sanitären Diskurs eingebaut werden, der in Buffons Histoire naturelle seinen wissenschaftlichen Bezugspunkt findet.

Neben vielem anderen finden wir auch hier das Motiv der schönen namenlosen Frau wieder, das die Europäer freilich auf ihrem eigenem Schiff heimsucht und obsessiv verfolgt, so dass sie alle Vernunft fahren lassen und zu Gefangenen ihrer eigenen Natur werden. Zumindest, was die einfachen Matrosen angeht. So darf denn auch hier der Verweis auf die Kraft der Natur im Gegensatz zur Ratio, der Vernunft, nicht fehlen, jenen grundlegenden Polen, an denen sich die europäische Aufklärung abarbeitete. Aber waren die Kräfte der Natur nicht stärker?

Dass Georg Forster, selbst noch reichlich jung an Jahren, nicht umhin konnte, seinerseits große, lebendige Augen zu machen und bei diesen Mädchen Schönheit zu konstatieren, macht uns zum einen darauf aufmerksam, dass hier erneut - wie schon in seiner Schilderung der Menschen auf den Kapverdischen Inseln - europäische Schönheitsbegriffe Verwendung finden, dass zum anderen aber auch die Möglichkeit und Fähigkeit besteht, die Schönheit eines Körpers 
ausgehend von bestimmten Punkten - hier insbesondere auch den Augen - ausgehend zu rekonstruieren, also auch eher hässliche Attribute gleichsam überspielen oder überstrahlen zu lassen. Nun gut: (Nicht nur) die Matrosen an Bord der Schiffe James Cooks wird dies wenig gekümmert haben, konnten sie doch hier Geschlechterbeziehungen ausleben, die in Europa selbst in ihren Sphären in den Hafenstädten der Welt wesentlich stärker tabuisiert waren. Hätte es sich um reine Prostitution gehandelt, so hätten sie nicht so den Verstand verloren und wären nicht so in Flammen aufgegangen, wie man zumindest anzunehmen berechtigt ist. In jedem Falle obsiegt ein patriarchalisches Denken, das man mit guten Gründen im Sinne von Jacques Derrida als phallogozentrisch bezeichnen darf.

Kehren wir nun aber rasch in unserem Exkurs ein letztes Mal zu Denis Diderots Supplément au Voyage de Bougainville zurück. Die Schönheit der Frauen ist im Diskurs der männlichen Reiseschriftsteller, Reisenden und Philosophen ein zentrales Thema nicht nur aufgrund der gleichsam innereuropäischen Geschlechterbeziehungen, sondern auch, weil sich im Bild der Frau stets das Andere, das es zu erobern und zu kolonisieren gilt, verbirgt. Die Frau und das Land, die Weiblichkeit und das kulturell Andere: Beide sind jeweils geschlechterspezifisch kodiert und zum Erobern freigegeben - gerade dann, wenn die begehrte Frau nicht nur eine geschlechtlich, sondern auch kulturell Andere in sich verkörpert.

Diderot, der ein feines Gespür für Höhepunkte hatte, war selbstverständlich jene Passage in Bougainvilles Reisebericht aufgefallen, in welcher sich urplötzlich eine antike abendländische Venus auf das Deck des französischen Schiffes begab und die anregendsten Posituren einnahm. Wir hatten die Szenerie in ihrer kunstvollen Anlage gesehen und gebührend bestaunt. Nun, der französische philosophe knüpfte daran eine Reihe von Überlegungen, die ich Ihnen nicht vorenthalten möchte. Der Schiffsgeistliche selbst habe angemerkt, erstens wieviel Wissen die Tahitianer in Liebesdingen erworben und gesammelt sowie tradiert hätten. Doch es gebe auch noch einen zweiten Punkt in seinen Anmerkungen:

[... 2. Der Unterschied in der Auffassung der Schönheit in der einen Gegend wo die Formen mit der Lust des Augenblicks zusammengebracht werden und bei einem Volk, wo sie in Bezug auf einen dauerhafteren Zweck geschätzt werden. Dort erwartet man von der Schönheit einen strahlenden Teint, eine große Stirn, große Augen, feine und zarte Züge, eine geschmeidige Figur, einen kleinen Mund, kleine Hände und einen kleinen Fuß ... hier hingegen spielt das alles fast keine Rolle. Die Frau auf die die Blicke sich richten und die das Begehren verfolgt ist eine die viele Kinder verspricht (die Frau des Kardinal d'Ossat) und zwar aktive, kluge, mutige, gesunde und robuste. Es besteht fast keine 
Gemeinsamkeit zwischen der Venus von Athen und der von Tahiti. Die eine ist die anmutige Venus, die andere die fruchtbare Venus. Eines Tages sagte eine Tahitianerin verachtend zu einer anderen Frau des Landes: „Du bist schön, aber du machst hässliche Kinder; ich bin hässlich, aber ich mache schöne Kinder und mich bevorzugen die Männer." ${ }^{\text {14 }}$

Das Signifikante an dieser Passage ist zum einen die Tatsache, dass eine Relativierung der Schönheitsbegriffe (und zwar wohlgemerkt allein bezüglich der Frau) prononciert vertreten wird, wobei nun die Frage der Utilität, der Nützlichkeit für den Mann und den Familiennachwuchs, in den Vordergrund geschoben wird. Wieder also sind es biopolitische Argumente, die von Diderot ins Feld geführt werden - ganz unabhängig von der Tatsache, dass die genderspezifische Dimension sich bezüglich der Schönheitsbegriffe selbst in Widersprüche verwickelt, da ein traditioneller, also männlich-europäischer Begriff der Schönheit auch im Diskurs der Insulanerinnen allem zum Trotz doch fortzuleben scheint.

Die Konstruktion von Alterität wird hier also problematisiert und damit auch die Universalisierung der europäischen Schönheitsbegriffe hinterfragt, indem gerade das europäische Element der Nützlichkeit als Hebel dient, alles scheinbar auf den Kopf zu stellen. Andererseits aber wird eine zweite Alterität unangetastet gelassen, jene nämlich der Geschlechterdifferenz, ist doch in der europäischen wie in der sogenannten tahitianischen Kultur die Frau vom Urteil des Mannes abhängig und letztlich an dessen Nützlichkeit sowohl im Sinne der Erzeugung männlicher Lust als auch im Sinne der Erzeugung von Nachkommenschaft ausgerichtet. Europa und seine Diskurse lassen schön grüßen!

So zeigt sich, dass wir in der Figur der Frau gerade im Reisebericht ein Motiv vorfinden, das eine überaus hohe Komplexität innerhalb der literarischen Tradition männlicher Reiseschriftsteller besitzt, wird doch gleichsam am Körper der Frau die Alterität der Kulturen, die Differenz der Geschlechter, die Macht der Kolonisierung, die Nützlichkeit abhängiger Existenz und die Ästhetik von Alltagskultur wie von Festtagskultur dargestellt. Diese Aufklärung zwischen zwei Welten hat die europäische Aufklärung bis weit ins 20. Jahrhundert aber nur wenig vorangetrieben. Mir scheint, dass in diesen genderspezifischen Bestimmungen etwas von dem aufscheint, was lange Zeit unabgegolten war und es wohl auch immer noch ist: eine Aufklärung hin zu einer Gleichstellung (des Körpers) der Frau, ihrer Körperpolitik als zentraler Dimension ihrer Emanzipation. Auch zur Diskussion dieser 'Altlasten' der europäischen Aufklärung dient das Supplément von Denis Diderot bis heute hervorragend.

14 Diderot, Supplément, S. $57 \mathrm{f}$. 
Allerdings: Denis Diderot war sich durchaus dieses Mankos, dieser Problematik, zumindest teilweise bewusst. Daher fügte er hier eine Anekdote ein, die eigentlich in einem Supplement zur Reise Bougainvilles nichts, aber auch gar nichts zu suchen gehabt hätte: Es ist die Anekdote von Polly Baker, die in Connecticut von ihren männlichen Richtern zum fünften Male verurteilt wurde, weil sie unehelich ein weiteres Kind auf die Welt gebracht hatte. Wieder die Frage nach Gender, Sexualität und gesellschaftlichen Normen?

Nein, keineswegs. Denn vielmehr zeigt sich, dass Polly Baker nur ein Opfer ihrer Situation und geschlechterspezifischen Lage als Frau ist und vom Verhalten der Männer abhängig bleibt, die aus ihr - wie in der Folge dann auch gezeigt wird - entweder eine Prostituierte oder eine ehrbare Frau und Mutter machen können. Diese Anekdote findet sich freilich auch in einem Text, den wir schon mehrfach erwähnt haben, nämlich Raynals Histoire des deux Indes. Dies ist Denis Diderot bewusst; und so verweist sein Supplément am Ende dieser Anekdote auch auf diese Tatsache, wobei er zugleich den guten Abbé Raynal gegenüber seinen zahlreichen Feinden in Schutz nimmt - so wie er auch wenig später eine Apologie zu ehren Raynals verfassen sollte. Hören wir kurz in den Dialog zwischen A und B:

B. Ich weiß nicht, ob der Abt Raynal in seiner Histoire du commerce de deux Indes die Fakten und den Diskurs berichtet hat.

A. Ein hervorragendes Werk und im Ton so anders als die vorausgehenden, dass man den Abt verdächtigt hat, fremde Hände benutzt zu haben.

B. Das ist ungerecht.

A. Oder eine Boshaftigkeit. Man zerstückelt die Lorbeeren, die das Haupt eines großen Mannes schmücken, und man zerstückelt sie so sehr, dass kein Blatt mehr davon übrig bleibt.

B. Aber die Zeit versammelt die verstreuten Blätter und setzt die Krone neu zusammen.

A. Aber der Mann ist tot; er hat unter der Beleidigung die er von seinen Zeitgenossen empfing, gelitten, und die Entschädigung, die er von der Nachwelt erhält, nimmt er nicht wahr. $^{15}$

Dies ist die Zeit, als Raynal bereits aus dem Anonymat seines Werkes herausgetreten war und Zuflucht in verschiedenen europäischen Ländern, darunter auch hier in Preußen und in Potsdam, nehmen musste. Sein Ruhm freilich wuchs dadurch nur mehr an und er wurde allenthalben als Verfasser eines der Bestseller der europäischen Lumiéres verehrt.

In der soeben angeführten Passage freilich wird ein intertextuelles und zugleich intratextuelles Spiel getrieben, blendet Diderot, der kräftig an der

15 Diderot, Supplément, S. 61. 
berühmten dritten Ausgabe der Histoire philosophique et politique des établissements des Européens dans les deux Indes mitgeschrieben hatte, doch den längst erhobenen Vorwurf ein, der Stil von Raynals Werk sei so unregelmäßig, dass es unmöglich allein aus der Feder Raynals stammen könne: Das Werk musste sich auch anderen Autoren verdanken. Einer dieser Autoren, nämlich Diderot selbst, macht mit einem kräftigen Augenzwinkern auf diesen Umstand aufmerksam. Im Übrigen zielten derartige Vorwürfe allein darauf ab, Raynal zu verunglimpfen und ihm den Ruhm seines unsterblichen Werkes noch zu Lebzeiten zu rauben. Dies aber sei nicht rechtens, habe der gute Abbé doch sein Werk selbst verfasst.

Natürlich wusste es Denis Diderot selbst besser. Die Triebfeder der französischen Encyclopédie, dies können wir hier erkennen, ist mit allen Wassern gewaschen. Und so führt uns der philosophe hier auch elegant ein Stückchen an der Nase herum, zugleich aber auch zu jenem Bestseller des 18. Jahrhunderts, der zum großen Nachschlagewerk der Aufklärung für die Beziehungen zwischen Europa und Außereuropa werden sollte: Raynals großer 'Kolonialenzyklopädie', der Histoire des deux Indes. Doch schließen wir an dieser Stelle unseren Exkurs ab und wenden wir uns wieder den weiteren Typen reiseliterarischer Orte zu.

\section{Drittens: Die Ankunft}

Innerhalb der verschiedenen Orte und räumlichen Bestimmungen, die den Reisebericht auszeichnen, ist ohne jeden Zweifel ein stets herausragender Ort die Ankunft des Reisenden am Ziel seiner Reise. Diese Ankunft kann auch als ein Höhepunkt gestaltet sein und nimmt gewiss eine Sonderstellung ein, muss aber im Sinne der hier zu unterscheidenden reiseliterarischen Orte keinen eigentlichen Höhepunkt darstellen.

Waren in den Texten La Condamines und Bougainvilles der Eintritt ins Amazonastiefland und das Erreichen Tahitis eingebettet in eine sich räumlich fortsetzende Reisebewegung, die fast übergangslos zur Heimkehr des Reisenden überleitet, so ist die Ankunft in einem emphatischen Sinne an das Erreichen eines bestimmten Ziels, dem ein längerer Aufenthalt gilt, gebunden. auch bei Alexander von Humboldt ist der Augenblick der Ankunft in Südamerika auf besondere Weise gekennzeichnet, auch wenn sich durch den Ausbruch einer Krankheit an Bord der Pizarro die Fahrtroute völlig veränderte und man nun nicht wie geplant im Hafen von La Habana auf Kuba sondern bei Cumaná im heutigen Venezuela anlandete. Die reiseliterarische Ausarbeitung der Ankunft ist in den Amerikanischen Reisetagebüchern wie auch im späteren Reisebericht 
der Relation historique eindrucksvoll gestaltet; zweifellos am beeindruckendsten aber ist die literarische Darstellung von Ankunft und erstem Tag in einem Brief vom 16. Juli 1799 an Alexanders Bruder Wilhelm:

Welche Bäume! Kokospalmen, 50 bis 60 Fuß hoch! Poinciana pulcherrima, mit Fuß hohem Strauße der prachtvollsten hochrothen Blüthen; Pisange, und eine Schaar von Bäumen mit ungeheuren Blättern und handgroßen wohlriechenden Blüthen, von denen wir nichts kennen. Denke nur, daß das Land so unbekannt ist, daß ein neues Genus welches Mutis (s. Cavanilles iconus, tom. 4) erst vor 2 Jahren publizirte, ein 60 Fuß hoher weitschattiger Baum ist. Wir waren so glücklich, diese prachtvolle Pflanze (sie hatte zolllange Staubfäden) gestern schon zu finden. Wie groß also die Zahl kleinerer Pflanzen, die der Beobachtung noch entzogen sind? Und welche Farben der Vögel, der Fische, selbst der Krebse (himmelblau und gelb)! Wie die Narren laufen wir bis itzt umher; in den ersten drei Tagen können wir nichts bestimmen, da man immer einen Gegenstand wegwirft, um einen andern zu ergreifen. Bonpland versichert, daß er von Sinnen kommen werde, wenn die Wunder nicht bald aufhören. Aber schöner noch als diese Wunder im Einzelnen, ist der Eindruck, den das Ganze dieser kraftvollen, üppigen und doch dabei so leichten, erheiternden, milden Pflanzennatur macht. Ich fühle es, daß ich hier sehr glücklich sein werde und daß diese Eindrücke mich auch künftig noch oft erheitern werden. ${ }^{16}$

Die Ankunft in Südamerika wird von Humboldt folglich als eine Ankunft in einem wissenschaftlichen Wunderland gestaltet, in welchem die europäischen Wissenschaftler zwischen amerikanischen Wunderpflanzen hin- und hergerissen werden. Die ungeheure Euphorie schlägt um in eine planlose Bewegung, in eine 'Narretei', in der sich die beiden Forscher ihren Gefühlen überlassen und in ihren Gegenständen ‘aufgehen'.

Aber auch auf einer persönlichen Ebene gesteht der preußische Gelehrte rasch ein, dass er sich hier sehr glücklich fühle und diesem Glücksgefühl auch während des sich nun eröffnenden Zeitraums seines Aufenthalts in den amerikanischen Tropen nichts entgegenstehe. Die Ankunft wird hier zu einem neuen Beginn, ja zum Auftakt einer Vita nova, die mit diesem Ankommen am Ziel der Wünsche bereits begonnen hat.

Zugleich eröffnet diese Ankunft einen neuen Zeitraum, in welchem das wahnwitzige Umherlaufen in einen kontrollierten, planmäßigen Gang der wissenschaftlichen Arbeiten beider Forscher übergehen muss und übergehen wird. Der reiseliterarische Ort der Ankunft wird bei Humboldt folglich zu einem Augenblick des Ausbruchs eines Glücksgefühls, aber auch des Neubeginns einer Zeitrechnung, die mit diesem Tage einsetzt.

16 Humboldt, Alexander von: An Wilhelm von Humboldt. In (ders.): Briefe aus Amerika 1799-1804. Herausgegeben von Ulrike Moheit. Berlin: Akademie Verlag 1993, S. 42. 
Doch dieser reiseliterarische Ort der Ankunft ist zugleich, häufig stärker noch als der Ort der Abreise, herausgehoben als ein Ort der Selbstvergewisserung, der Wahrnehmung des Anderen und der Problematisierung bereits vorgeprägter eigener Wahrnehmungsmuster, die sich hier erhärten oder verworfen werden. Nehmen wir hierfür ein Beispiel knapp hundert Jahre später, vom Ende des 19. Jahrhunderts, und aus einer anderen Weltgegend. In besonders klarer Form findet sich diese Selbstvergewisserung des reisenden Subjekts bei Richard Gordon Smith, einem viktorianischen Reisenden, der Japan zwischen 1898 und 1907 mehrfach besuchte. So heißt es in seinen Berichten aus dem 'Land der Götter':

Im Morgengrauen befand ich mich im Hafen von Nagasaki, Japan at last. Eine der Ambitionen meines Lebens war gewesen, dieses Land zu sehen, und hier war ich nun. Undeutlich noch zeichneten sich Hügel ab [...]. Die Kohlenboote kamen längsseits, und dann wurde das Japan meiner Einbildungskraft plötzlich lebendig. Die Kohlenverkäufer entpuppten sich als Mädchen und Frauen - alle stammten sie selbstverständlich aus den niederen Arbeiterklassen, und doch sah man ihren Gesichtern sofort an, dass dies ein Land in bester Stimmung war, ein Land, in dem selbst die Frauen aus der niederen Arbeiterklasse lächelnd zu einem aufsahen. ${ }^{17}$

Noch zeichnen sich die Konturen des Landes, die Konturen des Kommenden und bald schon Entdeckten, nur undeutlich und verwaschen ab. Doch es treten andere Bilder hervor. Bemerkenswert und aufschlussreich ist in dieser just auf den 24. Dezember 1898 datierten Bemerkung nicht allein, dass sich das fremde Land erneut in Gestalt einer sich dem männlichen Reisenden gegenüber freundlichen Unbekannten zeigt - zweifellos eine Variante des verbreiteten Rebecca-Motivs, das zugleich den geschlechterspezifisch keineswegs neutralen männlichen Blick des Reisenden 'freigibt'18 -, oder dass auch hier, noch von Bord des Schiffes aus, die verschiedenen räumlichen, aber auch sozialen Dimensionen des Ziellandes eingeblendet und erstmals eingeführt werden. Aufschlussreich ist vor allem die Tatsache, dass das Vor-Gewusste, das Japan of my imagination, in diesem Weihnachtsgeschenk der Ankunft plötzlich zum Leben erweckt wird. Der Reisende

17 Gordon Smith, Richtard / Manthorpe, Victoria (Hg.): Travels in the Land of the Gods. New York: Prentice Hall 1986, S. 14.

18 Vgl. hierzu Wolfzettel, Friedrich: Ce désir de vagabondage cosmopolite. Wege und Entwicklung des französischen Reiseberichts im 19. Jahrhundert. Tübingen: Niemeyer 1986, S. 33 ff. und $40 \mathrm{ff}$. Bereits die Reiseberichte und Chroniken des 16. Jahrhunderts zeigen freilich, dass das fremde Land, das in Besitz genommen werden soll, unter dem männlichen Blick stets weiblich metaphorisiert wird. Die libidinöse Struktur von Ent-deckung und In-Besitz-Nahme wird in der Gestalt, im begehrten Körper der unbekannten Frau manifest. Vgl. hierzu auch Hölz, Karl: Das Fremde, das Eigene, das Andere. die Inszenierung kultureller und geschlechtlicher Identität in Lateinamerika. Berlin: Erich Schmidt Verlag 1998. 
betritt nur physisch absolutes Neuland. In seinem Kopf aber hatten sich zuvor längst viele Bilder des von ihm dereinst zu besuchenden Landes gebildet, die nun, mit der Ankunft, einer Aktualisierung unterliegen. Diese vorab geformten Bilder können bisweilen so stark sein, dass sie die eigentliche Wahrnehmung von Land und Leuten in den Hintergrund drängen.

Der Übergang zwischen dem Vorwissen, das der britische Reisende vor allem seinen Lektüren verdankt, und der empirisch erfahrenen Realität vollzieht sich bei Richard Gordon Smith freilich erstaunlich harmonisch. Es scheint bei ihm nicht zu einem Kampf zwischen dem Vorgewussten und dem empirisch Wahrgenommenen, nicht zwischen den Japan-Bildern seiner Lektüren und den ersten Eindrücken bei der Ankunft im Hafen von Nagasaki zu kommen. Im reiseliterarischen Text werden die zuvor entworfenen Bilder vielmehr in Bewegung gesetzt, mit konkretem Leben, mit einem sinnlichen Lächeln erfüllt. Die hermeneutische Erfahrung der Konfrontation mit dem Anderen erscheint in dieser Passage als spannungsfreies Kontinuum, indem die in Gedächtnis und Einbildungskraft gespeicherten und fixierten Figuren ganz einfach lebendig und zu konkreten Gestalten im Reisebericht werden. Sie verkörpern die Bewegung, die der Text in mehrfacher Hinsicht re-präsentiert, und offerieren Deutungsmöglichkeiten, welche weit über die konkreten und empirischen Impulse in einer simplen Hafenszene hinausgehen. Der Reisende sieht, was er bereits vor seiner Reise vor sich liegen sah: Er erfährt, was er längst zu erfahren gelernt hatte. Man könnte sich an einer solchen Stelle fragen, ob es da der Reise noch bedurft hätte.

Ankunft als Erfüllung: Das so lange heiß ersehnte Ziel wird ganz so vorgefunden, wie es erwartet worden war. Dies muss freilich nicht immer der Fall sein. In Richard Gordon Smiths Reisebericht jedoch wird gerade diese hermeneutisch reflektierte Beobachterposition dazu benutzt, die Standortbestimmung sowohl auf der Ebene des erzählten Ichs (etwa in der Form der kursiv gesetzten erlebten Rede) als auch auf der Ebene des erzählenden Ichs (das die Ankunft als zurückliegende Erfüllung eines lang gehegten Kindheitstraums bezeichnet) gegenüber dem Leser deutlich zu markieren. Damit werden die literarischen Mechanismen des Reiseberichts gleichsam in ihrer konkreten Funktionsweise vor Augen geführt.

Die Ankunft am Ziel bezeichnet oft weniger den Ort erster Erfahrungen mit dem Anderen (diese werden bei Smith gerade nicht gemacht) als den Ort einer Selbstvergewisserung, einer Klärung der eigenen Motive, der eigenen Herkunft, des eigenen Standorts. Wie lange war diese Reise ersehnt worden! Und wie lange hatte es gedauert, bis sich die Wunschbilder des reisenden endlich konkretisieren konnten! Auch bei Richard Gordon Smith sind es vorgewusste Elemente, die - wie wir sehen konnten - schon bei anderen Reisenden zum Leben 
erwacht sind. So ließe sich sagen, dass der Reisebericht das Vor-Gewusste, die individuelle wie kollektive memoria in (lebendige) Bewegung (ver)setzt: Er verkörpert auch in diesem Sinne eine Literatur in Bewegung, die mehr ist als eine rein physische motion: Die innere Bewegung, die emotion, reist stets mit und transformiert oder bestätigt all jene Bilder, die sich im Vorgewussten herausgebildet hatten. Der reiseliterarische Ort der Ankunft markiert jenen Punkt, an dem beide Wissensstränge miteinander in Beziehung gesetzt werden.

\section{Viertens: Abreise vom Zielort}

Ein weiterer wichtiger reiseliterarischer Ort ist der Ort der Abreise von der Zielregion oder auch vom eigentlichen Höhepunkt einer Reise. An diesem Ort stoßen wir in der Regel auf einen weiteren semantischen Verdichtungspunkt, weil sich hier die verschiedenen Isotopien oder semantischen Bedeutungsebenen kreuzen und schneiden; und weil von diesem Ort aus verschiedenste Einsichten, Aussichten und Übersichten möglich und zum Teil auch notwendig sind. Denn der oder die Reisende zieht hier eine erste Bilanz und versucht sich zu vergewissern, welche Ereignisse wichtig und welche Ergebnisse herausragend waren, die den eigenen Aufenthalt im Zielgebiet der Reise betreffen. Es ist ein erster, aber keineswegs unwichtiger Punkt der Selbstvergewisserung, an welchem das gereiste Ich noch einmal die Positionen des reisenden Ichs vielfältig reflektieren kann und ein vorläufiges Bild der Reise entfaltet. Zugleich ist es auch der Ort einer vorläufigen Bilanz, welche der Zuhörerschaft präsentiert und erstmals diskutiert werden kann.

Dabei sind selbstverständlich unterschiedlichste Gestaltungen dieses reiseliterarischen Ortes denkbar. Zum einen kann der Reisende - wie etwa Alexander von Humboldt auf Cuba - noch einmal die verschiedenen Stationen seiner Reise in verschiedenen parallelen Sammlungen von Gegenständen Revue passieren lassen und damit die Resultate seiner gesamten Reise einerseits vergegenwärtigen und andererseits möglichst sicher für die Nachwelt aufbewahren. Die Aufspaltung in unterschiedliche Sammlungen diente in diesem Falle dazu, den eventuellen Verlust einer Sammlung zu kompensieren und durch die Existenz anderer, ebenfalls vollständiger Sammlungen auszugleichen, um so den materiellen Ertrag der Reise zu gewährleisten. Humboldt benutzte zugleich seinen zweiten Aufenthalt auf Kuba dazu, in Form seines kurzen kubanischen Tagebuches Ile de Cube, Antilles en général eine Gedächtnisstütze zu verfassen, die es ihm zu einem späteren Zeitpunkt erlauben sollte und erlaubte, der von ihm besuchten und untersuchten Insel eine eigene Monographie zu widmen. Diese monographische Studie erschien freilich erst Jahrzehnte später - und 
umso wertvoller waren jene Bemerkungen am Ausgang seiner Reise, die er im Jahre 1804 bereits festgehalten hatte.

Es ist aber auch denkbar, dass der Augenblick der Trennung vom eigentlichen Ziel der Reise in einem eher düsteren Licht steht und die oder der Reisende mit zumindest gemischten Gefühlen diesen reiseliterarischen Ort gestaltet. Auch hierfür möchte ich aus unserem bisherigen Korpus zwei Reiseberichte als Beispiele anführen. Denn ebendies ist zum einen bei Flora Tristan der Fall, die am Ort der Abreise eine kritische Bilanz ihres langen Aufenthaltes in Peru zieht und zu einem für sie selbst negativen Ergebnis gelangt. Denn sie hatte es weder erreicht, an das Erbe ihres verstorbenen Vaters zu kommen, noch wurde sie mit ihrer peruanischen Familie so vertraut, dass sie sich ernsthaft überlegt hätte, nicht mehr nach Frankreich zurückzukehren, sondern in Peru sesshaft zu werden. In dieser negativen Bilanzierung der Ergebnisse ihrer Reise erscheint zugleich auch der weitere Lebensweg der Reisenden selbst, insofern sie nun ihre erneute Einsamkeit, aber auch ihre wiedergewonnene Freiheit dafür nutzen muss, die Ziele ihres weiteren Lebens neu zu überdenken und festzulegen. So wird die Reise nach Lateinamerika für die französische Vorkämpferin der Frauen- wie der Arbeiterrechte ein abgeschlossenes Kapitel, an das sie später nicht mehr anknüpfen wollte.

Zum anderen denken wir an das Ende des Aufenthaltes von Bernardin de Saint-Pierre auf der damaligen Ile de France, dem heutigen Mauritius. Der französische Reisende und damalige Ingenieur zieht wie Flora Tristan ebenfalls eine negative Bilanz, die zugleich aber auch eine höchst kritische Bilanz des französischen Kolonialismus gleichsam aus einer Binnensicht ist. Bernardin de Saint-Pierre hat gelernt, diesen Kolonialismus und seine weltweiten Auswirkungen mit anderen Augen sehr kritisch zu sehen und seine eigene Position diesbezüglich neu zu bestimmen.

Der reiseliterarische Ort der Abreise vom Zielgebiet wird damit nicht nur zum Ort eines negativen Resümees, sondern zugleich zum Ort eines Auf Nimmerwiedersehens, eines endgültigen Abschieds von den kolonialen Tropen, denn hier mache man nur auf Kosten vieler anderer Fortune. Bernardin de Saint-Pierre lehnt diese Art von Gewinnerzielung fortan ab. Das gereiste Ich zieht dazu aber auch die Schlussfolgerung, seinerseits nie mehr in die Tropen gehen zu wollen, sondern in diesen kritischen Einsichten gegenüber dem Kolonialismus den eigentlichen Schatz, die eigentliche Fortune zu erblicken, die das Ich in den Tropen für sich gewinnen konnte. Der Autor von Paul et Virginie schließt damit das Kapitel seiner Reise in die Tropen ab, ohne freilich mit der außereuropäischen Welt selbst abzuschließen: Er wird zum Verfasser eines Reiseberichts, dem kein überragender Erfolg beschieden war, und zum 
Autor eines Bestsellers des späten 18. Jahrhunderts, mit dem er sich nicht nur in den französischen Literaturgeschichten bis heute verewigte.

So sind unterschiedlichste Gestaltungen dieses reiseliterarischen Ortes möglich- die angeführten Beispiele zeigen hier nur einige der höchst unterschiedlichen Gestaltungsmöglichkeiten auf. Wir hatten etwa- um noch ein anderes Beispiel kurz anzuführen- bei Hape Kerkeling gesehen, dass die Abreise in fast unmittelbarer Folge zum Erreichen des Höhepunktes der eigentlichen Pilgerreise, der Ankunft in Santiago de Compostela, erfolgt. Die Reflexion dieses Erreichen des Höhepunktes der Reise sowie die Fortsetzung dieser Reise in Form eines Rückfluges nehmen dann nur noch einen kleinen Teil des eigentlichen Reiseberichtes ein und konzentrieren sich eher auf das Erreichen eines fünften reiseliterarischen Ortes, der in der Folge abschließend besprochen sei.

\section{Fünftens: Die Rückkunft}

Abschließend sei als ein weiterer wichtiger reiseliterarischer Ort semantischer Verdichtung die Rückkehr zum Eigenen, die Rückkunft in der Heimat der oder des Reisenden benannt. Sie kann als schlichter Ausklang des Reiseberichts, als erneuerte Selbstbestimmung, als ein eher banales happy end, bisweilen aber auch als eigentliche Erfüllung des gesamten narrativen Zyklus konzipiert sein. Auch hier sind folglich die unterschiedlichsten Gestaltungsmöglichkeiten denkbar.

An diesem reiseliterarischen Ort kann sich der Kreis der gesamten Reise schließen. Damit wird ein kreisförmiger hermeneutischer Bewusstseins- und Erkenntniszusammenhang hergestellt, der wieder vom Eigenen her den gesamten Reiseverlauf semantisiert. Ein besonders anschauliches Beispiel bietet Bernardin de Saint-Pierres Voyage à l'Ile de France:

\footnotetext{
Man beeilte sich, eine letzte Mahlzeit zuzubereiten; aber man stand auf, setzte sich wieder, man aß keinen Bissen, wir konnten nicht von unserer Bewunderung der Erde Frankreichs lassen. Ich wollte mit meinem Gepäck an Land gehen; vergeblich rief man die Matrosen; sie hörten nicht mehr. Sie hatten ihre schönen Kleider angezogen: Sie waren von einer stummen Freude ergriffen; sie sagten kein einziges Wort: einige sprachen mit sich selbst. [. . .] Um mich her sah ich nur Leute, die bewegt waren. Ich rief einem Fischer und stieg in sein Boot. Als ich meinen Fuß auf die Erde setzte, dankte ich Gott, mich endlich wieder einem natürlichen Leben zurückgegeben zu haben. ${ }^{19}$
}

Das reisende Ich langt wieder in der Heimat an: Die äußere Bewegung macht einer inneren Platz, ein Ergriffensein breitet sich aus, das alle Matrosen, alle

19 Saint-Pierre, Voyage, S. $238 \mathrm{f}$. 
Mann an Bord erfasst. Die emotionale, von der inneren Bewegung bestimmte Rückkehr zum Eigenen öffnet sich im achtundzwanzigsten und letzten Brief auf eine neue Sichtweise des Eigenen, der Heimat Frankreich.

Der Brief ist auf den ersten Januar 1773 in Paris datiert, womit nicht nur ein neuer Ort des Schreibens - die französische Hauptstadt -, sondern auch der Beginn eines neuen Lebenszyklus symbolisiert wird. Eine neue Lebensphase beginnt. In diesem Brief beklagt der Reisende nicht nur das Fehlen literarischer Vorbilder bei dieser 'so interessanten Gattung, ${ }^{20}$ insoweit die großen Autoren des Jahrhunderts keine Reiseliteratur verfasst hätten, er macht nicht nur auf das schmerzliche Fehlen eines adäquaten Vokabulars für literarische Darstellungen tropischer Landschaften aufmerksam, sondern erhebt gegenüber den französischen Reiseschriftstellern seiner Zeit vor allem den Vorwurf, das Glück außerhalb der Grenzen ihres Heimatlandes gesucht beziehungsweise angesiedelt zu haben. ${ }^{21}$ Dieses Glück aber, so der Verfasser des Voyage à l'Ile de France, müsse man in Frankreich selbst suchen.

An diesem reiseliterarischen Ort zieht der französische Autor Bilanz und führt, in die Heimat zurückgekehrt, das Scheitern seiner eigenen Pläne vor, dank des französischen Kolonialismus für sich selbst Gewinne zu erwirtschaften. Er zieht daraus Rückschlüsse nicht nur individueller Art, sich künftig aus diesem Geschäft herauszuhalten. Hatte auch Bernardin die Reise in die Kolonien mit der Hoffnung auf finanziellen Gewinn verbunden, eine Hoffnung, die auch im Reisebericht bisweilen durchscheint, so steht am Ende dieses letzten Briefes seines Reiseberichts eine Entmythisierung der Tropen als Ort materiellen Reichtums, hofft der Erzähler doch, durch die Beschreibung der Schrecken der Sklaverei auf der Ile de France das Mitleid der europäischen Tyrannen erweckt zu haben und auf diese Weise mit seinem Reisebericht einen immateriellen Gewinn für die Menschheit in Sachen Menschlichkeit zu erzielen. So heißt es hier:

Pour toi, Nègre infortuné qui pleure sur les rochers de Maurice, si ma main, qui ne peut essuyer tes larmes, en fait verser de regret et de repentir à tes tyrans, je n'ai plus rien à demander aux Indes, j'y ai fait fortune. ${ }^{22}$

[Wenn meine Hand, die deine Tränen nicht trocknen kann, für dich, den unglücklichen Neger, der auf den Felsen von Mauritius weint, Deinen Tyrannen Bedauern und Reue einflößen kann, so habe ich nichts mehr zu erbitten von den beiden Indien, denn ich habe dort ein Vermögen gemacht.]

20 „Il nous manque un modèle dans un genre si intéressant“ (Ebda., S. 251).

21 Ebda., S. 255.

22 Bernardin de Saint-Pierre: Voyage à l'ile de France, S. 258. 
Die Rückkehr zum Eigenen entwickelt sich zu einer Anrufung, ja Beschwörung des lieu natal, ${ }^{23}$ des Geburtsortes, den der Philosoph nicht mehr zu verlassen brauche, um Gegenstände für seine Meditationen zu finden. Dieser lieu natal besitze, wie es am Ende des Reiseberichtes heißt, eine verborgene Anziehungskraft, eine unbeschreibliche Ergriffenheit, die kein Reichtum zu geben und kein Land zu vermitteln im Stande seien. ${ }^{24}$ Daraus aber heißt es nun, die Konsequenzen für ein künftiges Leben, für einen neuen Lebensabschnitt zu ziehen.

Die gesamte Dynamik des Reiseberichts, die Beschäftigung mit der exotisierten Alterität, welche Bernardin de Saint-Pierre dann in seinen tropischen Landschaften für Paul et Virginie ein letztes Mal literarisch brillant entstehen ließ, kommt so in einer Versöhnung mit dem Eigenen zum Stillstand. Der reiseliterarische Ort der Rückkunft situiert sich damit innerhalb einer hermeneutischen Bewegung, die den gesamten Text erfasst und bei Bernardin de Saint-Pierre in der Erkenntnis des berühmt gewordenen Schlussteils gipfelt. Der Kreis der Reise hat sich geschlossen; und mit ihm alle Verstehens- und Erkenntnisprozesse, die es der Leserschaft nahezubringen galt.

23 „Der Geburtsort besitzt eine verborgene Anziehungskraft, eine unbeschreibliche Ergriffenheit, die kein Reichtum zu geben und kein Land zu vermitteln im Stande wäre.“ (Ebda.) 24 Ebda. 